Aus der Klinik für Hals-Nasen-Ohrenheilkunde Prof. Dr. med. D. Beutner der Medizinischen Fakultät der Universität Göttingen

\title{
Occurrence and characteristics of allergic rhinitis in 195 patients with chronic rhinosinusitis
}

\author{
INAUGURAL-DISSERTATION \\ zur Erlangung des Doktorgrades \\ der Medizinischen Fakultät der \\ Georg-August-Universität zu Göttingen
}

\author{
vorgelegt von \\ Yiannis Pilavakis \\ aus \\ Larnaca, Zypern
}

Göttingen 2020 


\section{Betreuungsausschuss}

Betreuer/in:

Ko-Betreuer/in:

\section{Prüfungskommission}

Referent/in:

Ko-Referent/in:
Prof. Dr. med. F. Ihler

Prof. Dr. med. T. Buhl
Prof. Dr. med. F. Ihler

Prof. Dr. med. T. Buhl

Datum der mündlichen Prüfung: 02.12.2020 
Hiermit erkläre ich, die Dissertation mit dem Titel "Occurrence and characteristics of allergic rhinitis in 195 patients with chronic rhinosinusitis" eigenständig angefertigt und keine anderen als die von mir angegebenen Quellen und Hilfsmittel verwendet zu haben.

Göttingen, den 24.11.2020

(Unterschrift) 


\section{Table of Contents}

List of Figures ..................................................................................................... III

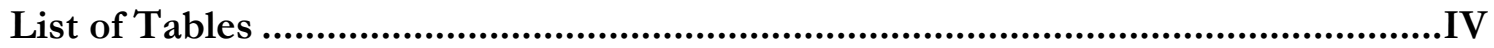

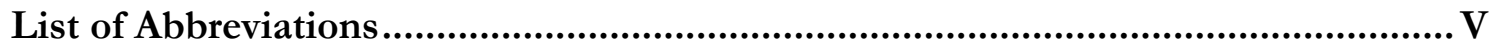

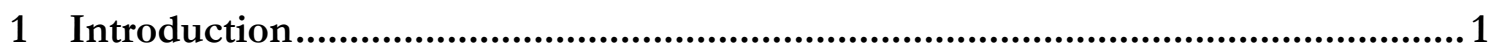

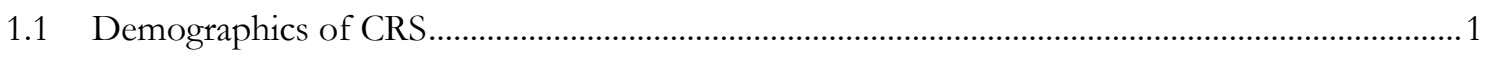

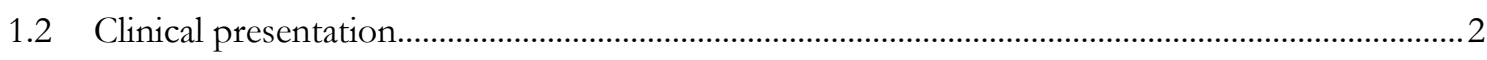

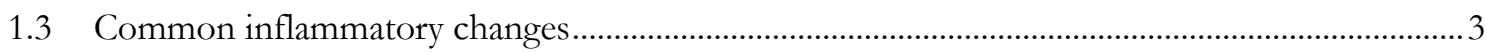

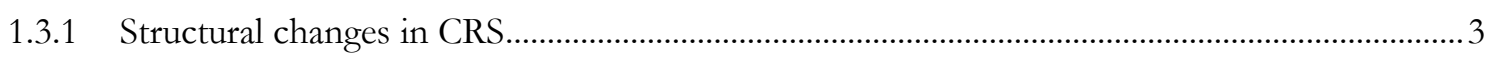

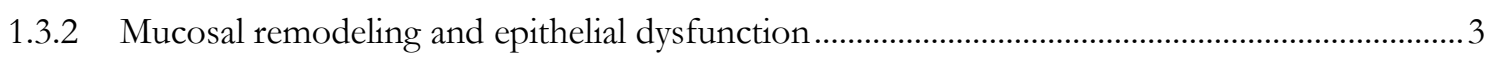

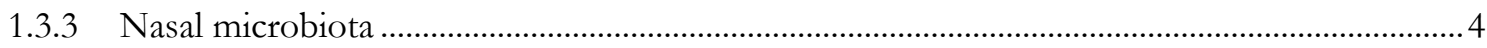

1.4 Different mechanisms - Innate and acquired immunity ...............................................................

1.5 Treatment options in CRS ...............................................................................................

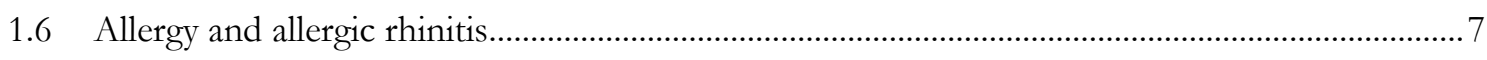

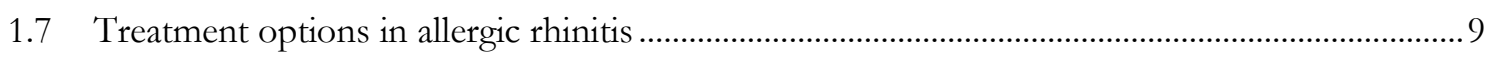

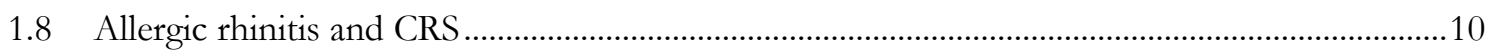

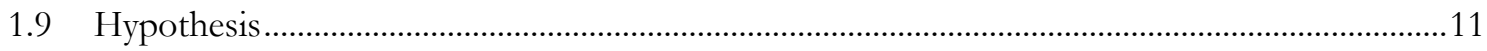

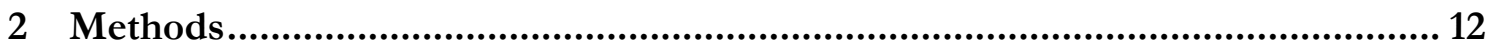

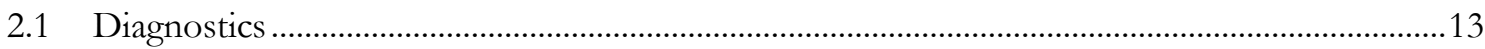

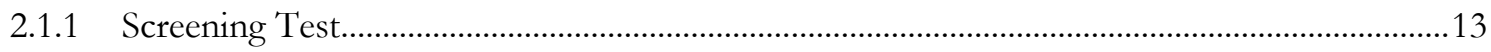

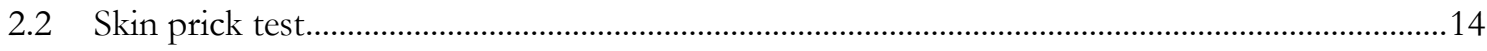

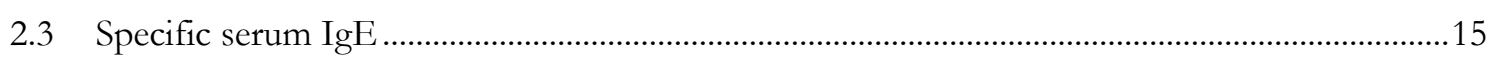

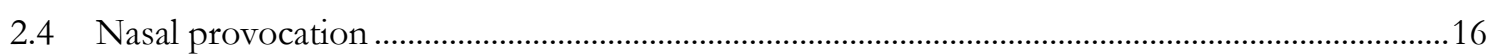

2.5 Computed Tomography and the Lund Mackay scoring system....................................................16

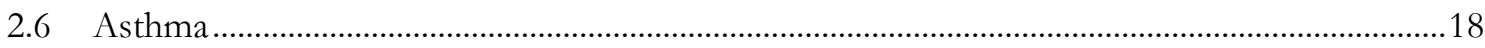

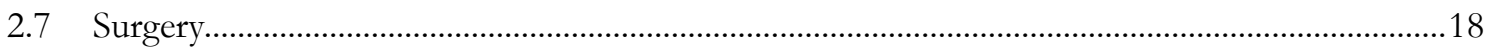

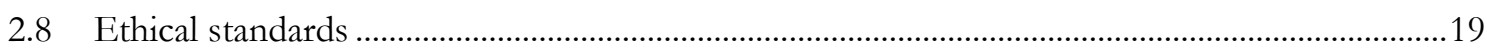

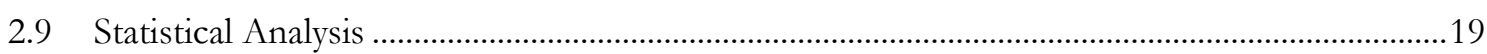

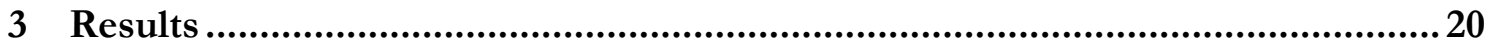

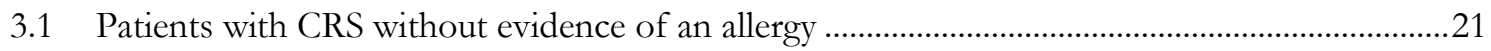

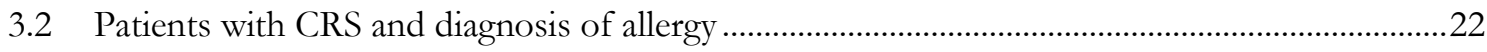

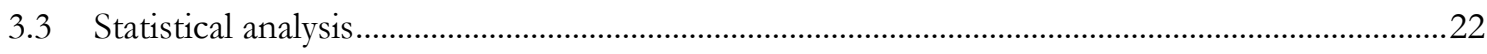

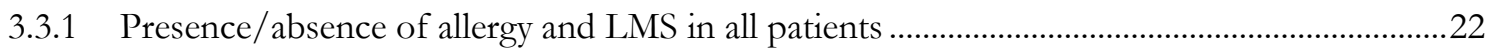

3.3.2 Presence/absence of allergy and LMS in patients with severe CRS ........................................23

3.3.3 Presence/absence of allergy and LMS in patients with CRSwNP ...........................................24

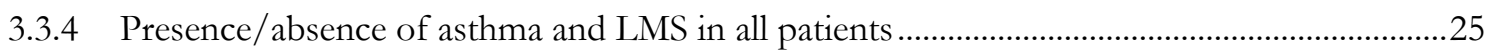




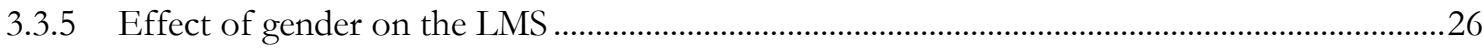

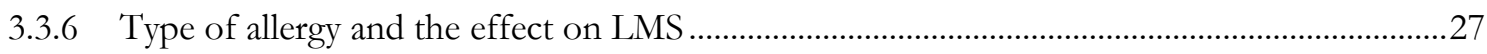

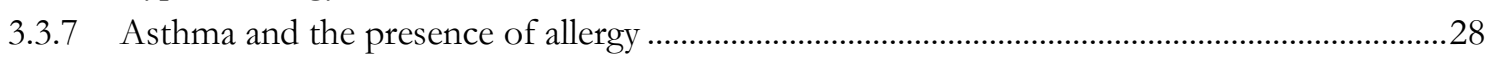

3.3.8 LMS in the presence of perennial allergy compared to non-allergic patients............................28

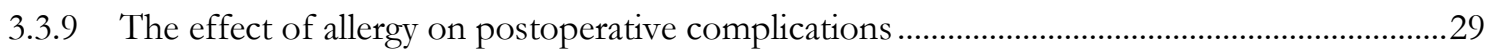

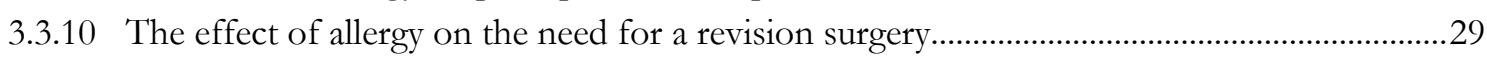

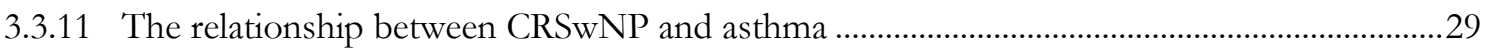

3.3.12 The relationship between mean age at first presentation and mean age at first operation between the two groups ……………………….........................................................30

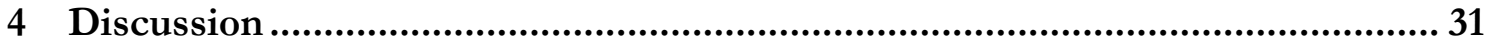

4.1 Evidence of a positive relation between allergy and CRS.............................................................32

4.2 Support that allergy plays a role in CRSwNP and not in CRSsNP ................................................

4.3 Evidence of no association between allergy and CRS severity ……………....................................

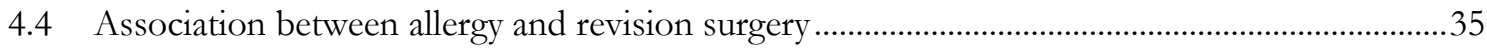

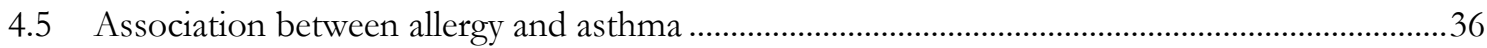

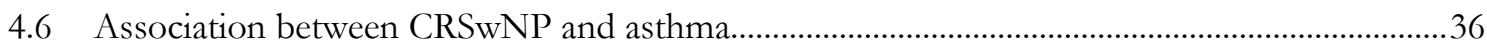

4.7 Association between allergy and postoperative complications .....................................................36

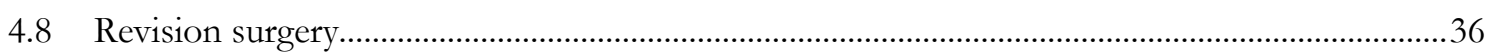

4.9 Age at first presentation, first operation and disease progression.................................................37

4.10 Allergy, atopy and inconsistencies in previous studies..................................................................38

4.11 Possible mechanism - local inflammatory pathway ………….......................................................

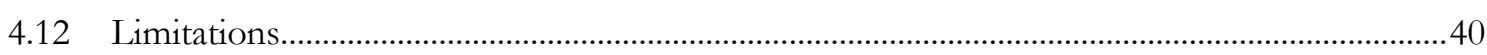

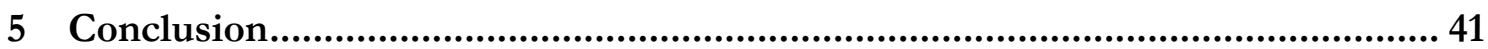

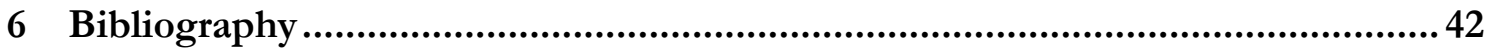




\section{List of Figures}

Figure 1: Flow diagram showing patient-selection.

Figure 2: Comparison of LMS in 115 patients with CRS without an allergy and 80 patients with CRS and an allergy.

Figure 3: Comparison of LMS in 60 patients with severe CRS.

Figure 4: Comparison of LMS in 45 patients with CRSwNP.

Figure 5: Comparison of LMS in 171 patients with CRS without asthma and 24 patients with CRS and a diagnosis of asthma.

Figure 6: Comparison of LMS between gender.

Figure 7: Comparison of LMS of 80 patients with CRS and allergy according to the 3 different allergy groups (seasonal, perennial and mixed). .28 


\section{List of Tables}

Table 1: EPOS 2012 diagnostic criteria for CRS 2

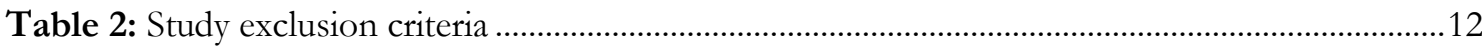

Table 3: Panel of aeroallergens tested for total IgE as initial serological screening (SX1 RAST).....13

Table 4: Rating of RAST screening test based on specific IgE levels

Table 5: Allergens that are routinely tested by skin prick test in our clinic

Table 6: The scoring system of LMS 


\section{List of Abbreviations}

\begin{tabular}{|c|c|}
\hline AFS & allergic fungal sinusitis \\
\hline $\mathrm{AR}$ & allergic rhinitis \\
\hline ARIA & allergic rhinitis and its impact on asthma \\
\hline CT & computed tomography \\
\hline CRS & chronic rhinosinusitis \\
\hline CRSwNP & chronic rhinosinusitis with nasal polyps \\
\hline CRSsNP & chronic rhinosinusitis without nasal polyps \\
\hline ENT & ear nose throat \\
\hline EMT & epithelial-to-mesenchymal transition \\
\hline ECP & eosinophil cationic protein \\
\hline EPOS & european position paper on rhinosinusitis and nasal polyps \\
\hline FcERI & Fc epsilon receptor I \\
\hline FESS & functional endoscopic sinus surgery \\
\hline $\operatorname{IgE}$ & immunoglobulin E \\
\hline $\operatorname{IgM}$ & immunoglobulin M \\
\hline IFN- $\gamma$ & interferon gamma \\
\hline IL-2 & interleukin-2 \\
\hline IL-4 & interleukin-4 \\
\hline IL-5 & interleukin-5 \\
\hline IL-13 & interleukin-13 \\
\hline $\mathrm{kU} / \mathrm{L}$ & kilo unit per litre \\
\hline LMS & Lund Mackay scoring system \\
\hline $\mathrm{OSA}$ & obstructive sleep apnea \\
\hline RAST & radioallergosorbent test \\
\hline SD & standard deviation \\
\hline $\operatorname{sIgE}$ & specific immunoglobulin $\mathrm{E}$ \\
\hline SPT & skin-prick test \\
\hline Th1 & T helper type 1 \\
\hline Th2 & T helper type 2 \\
\hline TGF- $\beta$ & transforming growth factor beta \\
\hline
\end{tabular}




\section{Introduction}

Chronic rhinosinusitis (CRS) is a clinical syndrome associated with persistent inflammation of the sinonasal mucosa. It consists of a heterogenous group of inflammatory diseases either accompanied by polyp formation (CRSwNP) or without polyps (CRSsNP) (Fokkens et al. 2012).

CRS is a very common condition and its prevalence is estimated to be $10-12 \%$ in Europe and the United States of America (Jarvis et al. 2012; Palmer et al. 2019).

The etiology of CRS is complex and multifactorial but at its center lies the concept of persistent mucosal inflammation. Research in the last 20 years has contributed to further understanding of this chronic upper airway disease. However, the precise causes are not fully understood. The proposed mechanisms for this enduring inflammation of the sinonasal mucosa include obstruction of the ostiomeatal complex, impaired mucociliary clearance, distortion of the nasal microbiome, biofilm formation and atopy (van Cauwenberge et al. 2006).

\subsection{Demographics of CRS}

CRS is amongst the most common conditions encountered in medicine and is associated with substantially impaired quality of life, reduced workplace productivity and significant treatment costs (Chivato et al. 2012; Ference et al. 2015; Erskine et al. 2017).

It is slightly more common among women and the incidence peaks between the ages of 4554. There appear to be sex differences also, as CRSsNP is commoner in women and CRSwNP is commoner in men (Beule 2015).

CRS is strongly associated with chronic conditions of the upper and lower airway tract, particularly with asthma. Other airway conditions include bronchitis, pneumonia, obstructive sleep apnea (OSA) and gastroesophageal reflux disease (Tan et al. 2013b).

In Germany, there are currently no reliable epidemiological data for the prevalence of CRS (Stuck et al. 2018). In Europe, the first population-based epidemiologic study in 2011 estimated the prevalence of CRS among adults at $10.9 \%$ with a significant geographical variation across the continent. The lowest prevalence $(6.9 \%)$ was reported in Helsinki (Finland) and Brandenburg (Germany) and the highest (27.1\%) in Coimbra (Portugal) (Jarvis et al. 2012).

In the United States of America, the prevalence is estimated at $11.5 \%$ of adults (Palmer et al. 2019) placing CRS among the ten most costly medical conditions with 11.1 million healthcare visits and 250000 sinus surgeries attributed to CRS (Tan et al. 2013a). 
In Asia, epidemiological studies have estimated the overall prevalence in China at 8\% (Shi et al. 2015) and 7\% in Korea respectively, with a significant rise documented within a twenty-year time period (Min et al. 1996).

\subsection{Clinical presentation}

CRS in adults is defined according to the latest European Position Paper on Rhinosinusitis and Nasal Polyps (EPOS) as symptomatic inflammation of the sinonasal mucosa that persists for at least twelve weeks with no complete resolution. It is characterized by two or more symptoms, one of which should be either nasal blockage/obstruction/congestion or nasal discharge (anterior/posterior nasal drip) - with or without facial pain/pressure - with or without reduction or loss of smell. Evidence of mucosal inflammation should be documented using either nasal endoscopy or computed tomography of the nasal sinuses (Fokkens et al. 2012).

Table 1: EPOS 2012 diagnostic criteria for CRS

\section{Criteria for the diagnosis of chronic rhinosinusitis with or without polyps}

Inflammation of the nose and paranasal sinuses by two or more symptoms, one of which should be either nasal blockage/obstruction/congestion, oronasal discharge (anterior/posterior nasal drip)

+ /- facial pain or pressure

$+/$ - reduction or loss of sense of smell

Supported with either:

endoscopic signs of disease including polyps, edema or mucopurulent discharge

or radiologic evidence of changes in the sinuses or ostiomeatal complex on computed tomography scan (CT)

One of the two cardinal symptoms (nasal blockage and nasal discharge) should be present in order to diagnose a patient with CRS (Fokkens et al. 2012).

This definition and classification has been proposed by consensus of an expert group on chronic rhinosinusitis and allergic rhinitis in 2012, in an aim to standardize previous inconsistencies regarding the disease.

CRS is typically classified into two clinically distinguishable phenotypes: chronic rhinosinusitis without nasal polyps (CRSsNP) and chronic rhinosinusitis with nasal polyps 
(CRSwNP). The majority of patients suffer from CRSsNP (75-80\%) and the rest $20-25 \%$ from CRSwNP. According to the proposed diagnostic plan, polyps should be endoscopically visualized at least in the middle meatus in order to be classified as CRSwNP. Another rare form of CRS is allergic fungal sinusitis (AFS), which is commonly characterized by a profound growth of a fungal organism, such as Aspergillus or Alternaria species. These fungi cause a local immune reaction predominantly with eosinophilia and clinically distinct due to the presence of thick mucin (Tyler and Luong 2018).

In general, the clinical presentation and symptoms of CRSsNP and CRSwNP overlap. There are common inflammatory pathways in both forms, but it appears from research done in the last years that both forms are underlined by distinct immunopathological mechanisms and patterns.

\subsection{Common inflammatory changes}

\subsubsection{Structural changes in CRS}

The nose and paranasal sinuses undergo a structural metamorphosis in CRS that appears radiologically and intraoperatively. Inflammation causes edema and swelling of the nasal mucosa, resulting in obstruction of the sinus ostia and mucus retention (Naclerio et al. 2010).

\subsubsection{Mucosal remodeling and epithelial dysfunction}

The respiratory epithelium provides a crucial barrier between the internal and external environment, as it is the site of primary attachment of inhaled irritants and pathogenic organisms. The concept of a dysfunctional interaction between host and environment is central in explaining CRS etiology and pathogenesis (Tan et al. 2010). The ability of the respiratory epithelium to provide protection depends partly on the physical ability of the epithelium to form tight junctions between cells preventing the entrance of pathogens. Tight junction-associated proteins and junctional adhesion molecules are central in this process and have been shown to be impaired in both forms of CRS in a process called epithelial-to-mesenchymal transition (EMT), a process occurring in mucosa during inflammation and ongoing repair (Khalmuratova et al. 2017).

During this process, there is a profound change in the morphology and junctional connection of epithelial cells to one another. Once activated, they proliferate and transform into mesenchymal cells. They gain migratory function and synthesize collagens and other matrix proteins, resulting in an expansion of the basement membrane. This mucosal remodeling impairs its normal protective function. The exact causes of this transition from epithelial to mesenchymal cells in CRS are not known but pathogens, irritants such as smoke, allergens and hypoxia are all supposed to induce this process (Zhang et al. 2016). 
Defects in the mechanical and immunological components of the epithelial barrier function are thought to play a central role in enabling foreign antigens to stimulate an immune response. An impaired epithelial immune barrier function makes the sinonasal mucosa more susceptible to antigenic exposure and is thought to be a significant causative mechanism in patients with CRS (Tieu et al. 2009).

In addition to the tight junctions between epithelial cells, mucociliary clearance of the upper airway has a major function in protecting against airborne pathogens. Successful clearance depends upon two factors; effective ciliary movement and regulation of the airway mucus layer. The coordinated beating of cilia directs mucus and trapped particles towards sinus ostia and eventually to the nasopharynx. The significance of this coordinated and efficient mucociliary clearance in maintaining paranasal sinus health is confirmed in patients and animal models with ciliary function defects or abnormal mucus production (London and Lane 2016).

Poor mucociliary clearance due to impaired cilia beating is a common finding in CRS. In such patients there is a compromised response to irritants such as allergens and microorganisms that usually stimulate and enhance cilia activity. This leads to a vicious cycle of stasis, further microbial colonization and chronic inflammation (Passàli et al. 1999).

\subsubsection{Nasal microbiota}

Changes in the nasal microbiota have also been implicated in the development of CRS. A distortion of the commensals in the microbiome of the nose and paranasal sinuses is thought to promote recurrent infections, and activate innate and adaptive immune responses. Several studies have shown a significant depletion in the microbiota diversity in patients with CRS compared to healthy controls suggesting that an imbalance (or dysbiosis) in the microbial community has a role in the development of CRS (Boase et al. 2013; Biswas et al. 2015).

Bacterial diversity and the composition of the sinonasal microbiome have been shown to be predictors of surgical outcome in cases of CRS, with patients having a better surgical outcome if there were more diverse bacterial communities present at the time of surgery (Ramakrishnan et al. 2015). On the contrary, increased bacterial load with Staphylococcus aureus and the presence of Staphylococcus aureus biofilms and superantigens are associated with eosinophilic inflammation and Th2 skewed response across all types of CRS (Foreman et al. 2011). A significant increase in the local immunoglobulin (IgE) levels has been shown, independent of serum IgE, supporting the notion that these bacterial superantigens can activate local B- and plasma cells (van Zele et al. 2004).

Not all studies agree with the causative role of the microbiota in the development of the disease. Researchers have indicated that patients with CRS show an abnormal reaction with prolonged inflammation even in the presence of normal bacterial communities (Aurora et al. 2013). The link between the sinonasal microbiome and its effect on CRS is complex due 
to the diverse nature of the disease and the distinct biogeographical patterns of bacterial communities among different patient populations (Biswas et al. 2015; Mahdavinia 2018).

The community of bacteria has also been shown to be altered in the nose in the presence of allergic disease. This leads to exaggerated immune responses, promoting chronic inflammation (Mahdavinia 2018).

\subsection{Different mechanisms - Innate and acquired immunity}

Respiratory epithelial cells have a central role in activating sinonasal innate immunity. These cells are stimulated once they recognize pathogenic molecular patterns as well as damage-related molecular patterns in their vicinity. Once activated, respiratory epithelial cells release a milieu of signaling molecules and cytokines that coordinate the interaction with other infiltrating and local inflammatory cells (Ooi et al. 2010).

Cytokines facilitate the communication between cells of the immune system, thus playing a central role in the inflammatory response present in chronic rhinosinusitis. Riechelmann et al. (2005) investigated the expression of various cytokines in the sinonasal secretions of patients and compared it to normal controls. They found that all of the investigated cytokines were considerably elevated in the CRS cohort.

There is substantial heterogeneity in the immunological mechanisms between CRSwNP and CRSsNP, with different inflammatory cell profiles and T-cell patterns. These distinct mechanisms originate from innate immune cells responding and interacting with the acquired immune system in different ways. Cells of the innate immune system contribute to the transition from an acute inflammatory response to sustained chronic inflammation. These cells including macrophages, dendritic cells, endothelial and epithelial cells, shift the inflammatory pathway into either a $\mathrm{T}$ helper type 2-(Th2) skewed inflammation or $\mathrm{T}$ helper type 1 (Th1) response (Ramanathan and Lane 2007). Th1 cytokine immune responses are typically associated with reactions against bacterial pathogens, whereas Th2 immune responses are classically seen in allergic and antiparasitic immune reactions. Within a healthy organism, both Th1 and Th2 immune responses coexist. However, their balance has been shown to be altered in patients with CRS as well as allergic disease (Cousins et al. 2008; Daines und Orlandi 2010).

CRSsNP is associated with a response that drives naive $T$ cell differentiation into a Th1 dominant inflammation, with high levels of interferon gamma (IFN- $\gamma$ ) as well as transforming growth factor beta (TGF- $\beta$ ). This TGF- $\beta$ pathway is upregulated in patients with CRSsNP and downregulated in CRSwNP. This is reflected histologically as fibrosis, basement membrane thickening and excessive collagen deposition, findings that are evident from the early stages of the disease in CRSsNP (van Bruaene et al. 2009). TGF- $\beta$ also regulates the function of immune cells, suppressing the activation of $\mathrm{T}$ cells and antibody secretion by $\mathrm{B}$ cells. In CRSsNP, sinonasal mucosa is swollen and profuse secretions are 
observed, often with pus, since hyperplasia of the submucosal glands is more common in CRSsNP (Kim et al. 2015).

CRSwNP is associated with a Th2 eosinophilic inflammation with an overexpression of eosinophils and related inflammatory products. It includes high interleukin-4 (IL-4), interleukin-5 (IL-5) and interleukin-13 (IL-13) levels, high eosinophil cationic protein (ECP), high IgE levels, upregulation of T-cell activation marker soluble interleukin-2 (IL-2) receptor alpha, deficit in regulatory T-cells and increased activity of T-helper cells. CRSsNP is associated with a Th1 inflammation and no deficit in regulatory T-cells (van Zele et al. 2006; Zhang et al. 2008). Edema formation is a prominent feature of CRSwNP, as well as formation of pseudocysts and lack of collagen production.

However, there are geographical exceptions to the above Th2 polarization in CRSwNP. It has been shown that patients from South China and other Asian regions develop nasal polyps with a neutrophilic cellular pattern, in the absence of the IL-5 activation (Zhang et al. 2006).

In patients with allergic rhinitis, the production of IL-4 activates naïve T lymphocytes promoting their differentiation into Th2 CD4+ cells. In this mechanism of immunoglobulin class switching, mature $B$ cells shift production from immunoglobulin $M$ (IgM) to $\operatorname{IgE}$ antibodies. The class switching process is modulated by various cytokines, primarily IL-4 and IL-13 produced by activated T cells. As a result, stimulated plasma cells induce $\operatorname{IgE}$ release, with the subsequent allergic response upon allergic exposure (Stone et al. 2010).

\subsection{Treatment options in CRS}

CRS is a challenging disease to treat. Common treatment options include intranasal (topical) corticosteroids, saline irrigation, antibiotics and oral steroids (Fokkens et al. 2012; Head et al. 2016; Luk and DelGaudio 2017).

Patients with extensive disease or refractory cases progress to functional endoscopic sinus surgery (FESS), with continued medical therapy thereafter (Hellings et al. 2017). The array of endoscopic endonasal sinus operations has considerably increased in the last 30 years. Improved endoscopic techniques along with advances in imaging systems allow surgeons to perform a variety of endonasal procedures including infundibulotomy, ethmoidectomy or extended surgery of the skull base, frontal and sphenoid sinus. The objective of endonasal sinus surgery is to improve drainage of nasal sinuses and remove relevant foci of disease while preserving normal mucosa as much as possible (Weber and Hosemann 2015).

These treatment strategies focus on symptomatic control by reducing the mucosal inflammation and bacterial burden of paranasal sinuses. Although they are effective for the majority of patients (Stuck et al. 2018), there is still a significant proportion of patients who 
respond only partly to these therapeutic interventions, particularly patients with CRSwNP (Hopkins et al. 2009; DeConde et al. 2017).

\subsection{Allergy and allergic rhinitis}

An allergic response is an abnormal reaction of the human body when in contact with normally harmless substances that are called allergens. It is initiated by specific immunologic mechanisms. Upon exposure to an allergy source, type I hypersensitivity reaction against that allergen occurs. The antigen is presented by a Th2 lymphocyte, which in terms initiates the production of IL-4. These cells interact and activate B cells to begin producing large quantities of $\mathrm{IgE}$ antibodies that circulate in the blood, eventually binding to an IgE-specific receptor, the Fc epsilon receptor I (FceRI) on the surface of mast cells and basophils. The individual at this stage is said to be sensitized to the allergen. Upon a secondary exposure to the same allergen, the allergen is attached to $\operatorname{IgE}$ molecules that are bound on the surface of granulocytes. Cross-linking of the $\mathrm{IgE}$ and $\mathrm{Fc}$ receptors occurs activating mast cells and basophils to undergo degranulation, releasing histamine and an array of other pro-inflammatory mediators such as cytokines, leukotrienes, interleukins, prostaglandins and growth factors into the surrounding tissue. This directly evokes a large variety of tissue responses, including vasodilation, increased vascular permeability, increased adhesion molecule expression, mucous secretion and smooth muscle contraction. Depending on the immune system of the individual, the allergen and the entry point, the symptoms can be systemic or localized to particular body systems (Denburg 2013).

Allergic diseases rank at first place among chronic diseases in childhood and adolescence in Germany, with $20-25 \%$ of individuals being currently affected by one of the atopic diseases. The three most important conditions are atopic eczema/dermatitis, allergic rhinitis and asthma. Interviews and questionnaires relating to doctor diagnosed allergic diseases in Germany yielded a prevalence of $13.2 \%$ for atopic dermatitis, $10.7 \%$ for allergic rhinitis and $4.7 \%$ for asthma in children and adolescents (Schlaud et al. 2007). The prevalence of allergic disease (similar to other allergic conditions) affecting both adults and children is reported to be increasing. This trend has been shown worldwide as well as specifically in Germany (Maziak et al. 2003; Arbes et al. 2005).

The dramatic increase in the prevalence of allergic disease that has been documented in the last 50 years is thought to be the result of changes in environmental factors and coincides with our increasingly modern Westernized lifestyles. According to the "hygiene hypothesis", alteration of the microbial exposure along with the increasing use of antibiotics predisposes individuals to allergic disease. This is specifically true during early life as it can strongly influence immune system maturation (Daley 2014; Burbank et al. 2017; Murrison et al. 2019). 
In addition, epidemiologic studies have demonstrated that urbanization, which is linked to elevated exposure to air pollutants is associated to the increasing incidence of respiratory allergic diseases and bronchial asthma observed in most industrialized countries. Airborne air pollutants, which have increased in the atmosphere, are thought to enhance IgEmediated response to aeroallergens and promote airway inflammation (D'Amato et al. 2016).

Allergic rhinitis involves hypersensitivity symptoms occurring in the nose and paranasal sinuses. Symptoms include nasal blockage, rhinorrhea, nasal itching and sneezing. The majority of patients experience accompanying ocular symptoms such as tearing, itching and redness. Allergic rhinitis is the commonest cause of reversible nasal congestion. Its prevalence is estimated between $10 \%$ and $20 \%$ depending on geographical region, however it is thought that a significant proportion of cases remain undiagnosed (Settipane and Charnock 2007). The frequency of allergic rhinitis increases with age, and the majority of patients (80\%) will experience their first symptoms before the age of 20 . In children there is a higher incidence amongst boys, but in adults, it affects both sexes equally (Skoner 2001). A large demographic study regarding allergic diseases in adult subjects living in Germany published in 2013 identified a lifetime prevalence of $14.8 \%$ for allergic rhinitis (Langen et al. 2013).

Allergic rhinitis, similar to other respiratory-tract allergies has a considerable impact on the quality of life of patients and appears to affect them to the same extent as that of other chronic diseases such as diabetes and cardiovascular disease (Petersen 2008).

Allergic rhinitis appears to have a strong genetic component as the tendency to develop Th2 lymphocyte immune responses, with $\operatorname{IgE}$ and mast cells is inherited by atopic patients. Once sensitization has occurred, subsequent exposures to the same allergen generate a cascade of events that result in allergic symptoms.

Conventionally, allergic rhinitis as been classified either as perennial or seasonal, according to the timing and duration of the allergen exposure (Gentile et al. 2013). Approximately $20 \%$ of all cases were thought to be strictly seasonal, $40 \%$ perennial and $40 \%$ mixed (perennial with seasonal exacerbations). The commonest causative allergens for seasonal allergic rhinitis are early blossoming plants such as birch, alder and hazel and pollen of grass or rye. The commonest allergens contributing to perennial allergic rhinitis include house-dust mite, molds, and animal dander from cats, dogs and horses (Greiwe and Bernstein 2019). However, some patients that are sensitized to seasonal allergens experience symptoms throughout the year and some that are sensitized to perennial allergens experience symptoms only during some months of the year. Because of the limitations of the above classification from a therapeutic standpoint and its poor association with clinical symptoms, a new Allergic Rhinitis and its Impact on Asthma (ARIA) classification was proposed in 2001 by the World Health Organization. This new 
classification, categorizes allergic rhinitis according to severity and symptom duration (Johansson et al. 2004b; Bauchau and Durham 2005).

The only up-to-date publication regarding allergic rhinitis that exists in Germany from the most recent Health Survey, reported that based on blood samples of 7025 individuals $33.6 \%$ of the participants were sensitized to common aeroallergens. $22.0 \%$ of participants were sensitized to pollen of grass, $19.0 \%$ were sensitized to pollen of early blossoming plants, $15.9 \%$ to house dust mite, $10.0 \%$ to animal dander and $4.6 \%$ to fungi (Haftenberger et al. 2013).

The diagnosis of allergic rhinitis is based on the demonstration of the production of serum allergen specific immunoglobulin $\mathrm{E}$ (sIgE) or positive skin-prick test (SPT) in patients with a positive history of allergic symptoms. In some cases, especially when it involves seasonal allergic rhinitis, a nasal provocation test can be used to confirm the clinical diagnosis. Perennial allergic rhinitis is often more challenging to detect than seasonal allergic rhinitis due to the overlap with chronic rhinosinusitis, respiratory infections, and vasomotor rhinitis (Seidman et al. 2015).

\subsection{Treatment options in allergic rhinitis}

The treatment of allergic rhinitis consists of 3 major pillars: a. Environmental control measures and avoidance, b. Pharmacological management and c. Immunotherapy.

Environmental control measures and avoidance of allergen exposure can be applied in all types of allergens. Patients are actively engaged in using strategies that aim to minimize exposure to specific allergens and thus reduce symptoms of allergic rhinitis. These approaches for minimizing exposure to various seasonal and perennial allergens can be quite challenging, expensive and often impractical (Seidman et al. 2015).

Several pharmacologic options for the management of allergic rhinitis exist including oral and intranasal corticosteroids, oral and topical antihistamines, decongestants, intranasal anticholinergics, and leukotriene receptor antagonists (Fokkens et al. 2012). The use of intranasal corticosteroids is the most effective symptomatic treatment of allergic rhinitis, which decreases all symptoms, including ocular ones. It is currently the mainstay of symptomatic treatment and is used alone or in combination with intranasal antihistamines.

Antihistamines have been shown to significantly reduce nasal congestion, conjunctivitis, sneezing and rhinorrhea when used orally or topically. Oral antihistamines have been used for more than 50 years, providing relief from allergic symptoms. Second generation oral antihistamines have been developed to reduce sedation and lower the anticholinergic side effects with enhanced reduction of symptoms such as runny nose, nasal itching and sneezing compared to older histamine receptor antagonists (Kawauchi et al. 2019). 
The combination of topical corticosteroid with intranasal antihistamine has been shown to be superior to monotherapy in providing control over allergic rhinitis. Alternative therapies, such as homeopathy, probiotics, herbal preparations and acupuncture have produced some positive results in small trials but there is still insufficient data, and are thus not recommended by Allergic Rhinitis and its Impact on Asthma (ARIA) (Schröder et al. 2017).

Immunotherapy should be considered in all patients with moderate or severe persistent allergic rhinitis. Immunotherapy, which has been shown to be safe in children and adults, is the only causal therapy that can change the natural course of allergic rhinitis and can prevent exacerbations. It entails a small amount of allergen extract administered sublingually or subcutaneously over the course of three to five years (Pfaar et al. 2014).

\subsection{Allergic rhinitis and CRS}

CRS and allergy to aeroallergens are two of the most common reasons for presentation of patients to the ear nose throat (ENT) practitioner. The two entities may be independent, but often they coexist in the same patient (Geißler and Guntinas-Lichius 2015).

On a microscopic level, the presence of allergy has been shown to alter the sinus mucosa consistency (Passàli et al. 1995) and the cilia of the respiratory epithelium (Bozzo et al. 2005). In addition, it has been reported that allergic subjects tend to have abnormal nasal airflow and mucociliary clearance values compared to healthy controls. These abnormalities were associated significantly with higher nasal sinus CT scores, thus predisposing patients to rhinosinusitis and sinonasal inflammation (Alho 2004).

Evidence of susceptibility to (acute) sinusitis has also been shown on an experimental level. In a mouse model of sinusitis using intranasal inoculation with Staphylococcus pneumonia, mice with ongoing nasal allergic inflammation had significantly more bacteria and more inflammation in their sinus mucosa (Blair et al. 2001).

In human subjects, Baroody et al. (2008; 2012) showed an increase in vascular permeability associated with an eosinophilic influx into the ipsilateral maxillary sinus after nasal challenge with allergens. Similar results with sinus inflammation were detected by lavage sampling during the allergen season.

Suzuki et al. (1999) identified similar results in a cellular and molecular level. The pathological features of paranasal sinus effusion and mucosa were compared between patients with chronic rhinosinusitis with and without an allergy. The number of activated eosinophils/neutrophils, and the concentration of IL-5 was higher in paranasal sinus effusion from patients with allergic sinusitis.

On a clinical level, a cause and effect relationship between allergic rhinitis and CRS has been proposed for years, based mainly on epidemiological studies. For many studies 
performed in the past, no direct comparison can be made, as they have often grouped together patients with CRSsNP and CRSwNP, had heterogeneity in their design, inclusion criteria used for the diagnosis of CRS and allergens studied (Terzakis and Georgalas 2017). Therefore, there is still controversy over disease causality and uncertainty whether atopic conditions can aggravate disease severity, accelerate its recurrence or just be a diseasemodifying factor.

Two systematic reviews of the scientific literature performed in the last years (Georgalas et al. 2014; Wilson et al. 2014) as well as a study investigating whether specific allergen sensitization is correlated with sinonasal radiographic opacification (Brook et al. 2017) have questioned a direct causative link between allergy and CRS. They report no association between atopy status, disease severity or recurrence in patients with CRS. They question further the direct causality of allergy on CRS and indicate that there is no increase in the incidence of infectious rhinosinusitis during the pollen season in pollen-sensitized individuals.

\subsection{Hypothesis}

Although our understanding of the pathophysiological mechanisms of CRS has significantly improved, the relationship between CRS and allergic rhinitis to inhalant allergens remains unclear due to controversial findings and difficulties in comparing studies due to diversity in the methodologies. To further investigate this association, we conducted a retrospective study of all consecutive patients between November 2012 and November 2016 who presented to our otorhinolaryngology clinic with evidence of CRS and had a positive screening test for inhalant allergy (SX1 radioallergosorbent test: RAST).

We hypothesize that allergic inflammation would actively impair the normal sinus physiology in several ways, thus predisposing and exacerbating chronic rhinosinusitis. Allergic edema causing ostial obstruction and altering the normal drainage and ventilation of the sinuses would promote mucus accumulation and retaining of sinus secretions. This could impair ciliary movement, promoting bacterial growth within the sinuses, resulting into a chronic inflammation. We assumed that patients with a proven inhalant allergy would have more severe radiological evidence of disease compared to patients without an allergy.

Secondarily, other factors such as polyposis, gender and asthma will be investigated whether they influence CRS severity. Finally, we will analyze whether the presence of allergy affects the complication rate and need for a revision surgery. 


\section{Methods}

A retrospective study of 938 consecutive patients who were referred to our clinic between November 2012 and November 2016 was performed. All of these patients presented with rhinological symptoms due to CRS and had a positive screening test for inhalant allergy (SX1 RAST). Patients were included in our study if there was a complete sinus workup at our institution, if they satisfied the inclusion criteria for the diagnosis of CRS based on the EPOS-2012 criteria and if they did not satisfy any other of the exclusion criteria. After applying these criteria, 195 patients were included. For a more detail presentation, see Table 2 and Figure 1.

Table 2: Study exclusion criteria

\section{Exclusion Criteria}

Patient $<18$ years of age

Incomplete sinus work-up

Diagnosis not satisfying EPOS 2012 criteria

Previous surgery to the sinuses and nasal septum

Prior trauma to the nose and mid-face

Congenital anatomical variations such as cleft lip

Benign or malignant tumors of the nose and nasal sinuses

Immunocompromised patients

Inflammatory and autoimmune conditions

We recorded demographic data, CRS subtype, asthma status and other relevant comorbidities. We performed extensive allergic diagnostics, including skin-prick testing and serum $\operatorname{IgE}$ measurements to all patients and when needed nasal provocation.

In terms of the complete sinus workup, this included history taking, nasal endoscopy with 30-degree endoscope and a computed tomography (CT) scan of the nasal sinuses available in electronic form in our database (PACS, General Electric, USA). The radiologic evidence and severity of CRS was scored using the LMS. 


\subsection{Diagnostics}

All the allergy diagnostic was performed based on the 2014 guidelines of the German Society of Allergy and Immunology (Pfaar et al. 2014).

\subsubsection{Screening Test}

All our patients were initially seen in our general otorhinolaryngology clinic where an in vitro screening test for inhalant allergy (SX1 RAST) was performed. This investigation tests the 8 most common aeroallergens that are present in the regional population. They are listed in table 3. Patients with a positive screening test (RAST 1 or above) were seen in our specialized allergy outpatient's clinic.

Table 3: Panel of aeroallergens tested for total $\operatorname{IgE}$ as initial serological screening (SX1 RAST)

\begin{tabular}{|ll|}
\hline Common name & Species \\
\hline House dust mite & Dermatophagoides pteronyssinus \\
\hline Dog & Canis familiaris \\
\hline Cat & Felis domesticus \\
\hline Timothy-grass & Phleum pratense \\
\hline Cultivated rye & Secale cereal \\
\hline Fungi & Cladosporium herbarum \\
\hline Birch & Betula pendula \\
\hline Mugworth & Artemisia vulgaris \\
\hline
\end{tabular}

ImmunoCAP® Total $\operatorname{IgE}$ measures $\operatorname{IgE}$ in human serum or plasma in concentrations between 0.1 to 100 kilo unit per litre $(\mathrm{kU} / \mathrm{L})$ stimulation. Serum total $\mathrm{IgE}$ levels greater than $0,35 \mathrm{kU} / \mathrm{L}$ were considered elevated, and thus a positive screening test. Table 4 lists the rating of RAST screening test based on the $\operatorname{IgE}$ levels. For the in vitro total serum $\operatorname{IgE}$ measurements we used the ImmunoCAP® System (Phadia AB, Uppsala, Sweden). 
Table 4: Rating of RAST screening test based on specific IgE levels

\begin{tabular}{|ccl|}
\hline $\begin{array}{c}\text { RAST } \\
\text { rating }\end{array}$ & $\begin{array}{c}\text { IgE levels } \\
(\mathrm{kU} / \mathrm{L})\end{array}$ & Comments \\
\hline 0 & $<0.35$ & Absent or undetectable allergen specific IgE \\
\hline 1 & $0.35-0.69$ & Low level of allergen specific IgE \\
\hline 2 & $0.70-3.49$ & Low to moderate level of allergen specific IgE \\
\hline 3 & $3.50-17.49$ & Moderate level of allergen specific IgE \\
\hline 4 & $17.50-49.99$ & Moderate to high level of allergen specific IgE \\
\hline 5 & $50.00-100.00$ & High level of allergen specific IgE \\
\hline 6 & $>100.00$ & Extremely high level of allergen specific IgE \\
\hline
\end{tabular}

\subsection{Skin prick test}

For those individuals with a positive screening test, an appointment in our specialized allergy outpatient's clinic was followed. A detailed allergy-specific history was acquired, followed by skin prick testing (Table 5). Allergens, which are routinely tested in our allergy clinic, include extracts of tree pollen (birch, alder, hazel), grass pollen (cultivated rye, timothy-grass), weed pollen (ragweed, pellitory, ash), the two commonest house dust mites (Dermatophagoides pteronyssinus und Dermatophagoides farinae), three mold species (Alternaria alternata, Aspergillus fumigatus, and Cladosporium herbarum), dog and cat dander. Histamine was used as a positive control, and saline as a negative control. The test was read 20 minutes after applying the allergens. It was regarded as positive when the skin reacted with a wheal size of greater or equal to $3 \mathrm{~mm}$ greater than the negative control. We performed the standardized procedure previously described (Dreborg and Frew 1993; Ruëff et al. 2011). 
Table 5: Allergens that are routinely tested by skin prick test in our clinic

\begin{tabular}{|ll|}
\hline Common name & Species \\
\hline Birch & Betula pendula \\
\hline Hazel & Alnus incana \\
\hline Roggen & Corylus avellana \\
\hline Timothy-grass & Secale cereale \\
\hline Ragweed & Pbleum pratense \\
\hline Pellitory & Ambrosia artemisiifolia \\
\hline Ash & Parietaria judaica \\
\hline House dust mite & Fraxinus excelsior \\
\hline House dust mite & Dermatophagoides pteronyssinus \\
\hline Mold & Dermatophagoides farinae \\
\hline Mold & Alternaria alternata \\
\hline Mold & Aspergillus fumigatus \\
\hline Dog dander & Cladosporium herbarum \\
\hline Cat dander & Canis familiaris \\
\hline & Felis domesticus \\
\hline
\end{tabular}

\subsection{Specific Serum IgE}

After having a positive skin prick test, we tested specific serum $\operatorname{IgE}$ measurements in all our patients during their appointment in our specialized allergy clinic. For the in vitro specific serum IgE measurements we used the ImmunoCAP® System (Phadia AB, Uppsala, Sweden). This test enables an objective measurement of the circulating $\operatorname{IgE}$ antibodies to specific allergens in human serum or plasma thus allowing us to identify sensitization to a specific allergen (Johansson 2004a; Renz et al. 2010). 


\subsection{Nasal provocation}

In patients with house dust mite allergies, in those with discrepancies between medical history and skin prick test/specific IgE results, or multisensitized patients, a nasal provocation test (LETI, Barcelona, Spain) was used. We use the technique previously described (Riechelmann et al. 2003; Gosepath et al. 2005) with extracts administered intranasally in increasing concentrations of 1:10000, 1:1000, 1:100, 1:10, 1:1 with a waiting time of 15 minutes before each measurement. At each concentration, we measured nasal flow using acoustic rhinometry and documented clinical symptoms.

Once the diagnostic work-up was performed, subjects were categorized as allergic, or nonallergic. A concise definition of allergy is not uniformly accepted, but for this study our criteria for the diagnosis of allergic rhinitis was a positive history of allergic rhinitis symptoms combined with a matching positive skin prick test and elevated specific IgE levels for the same allergen. In some patients (23 out of 80 ) allergic rhinitis was additionally confirmed with a nasal provocation test as described above.

\subsection{Computed Tomography and the Lund Mackay scoring system}

Computed tomography (CT) scans of the nasal sinuses were scored using the Lund Mackay scoring system (LMS). The LMS was developed in the mid 1980s as a tool to assess the extent of CRS and facilitate treatment decisions (Lund and Mackay 1993). It is an objective measure of quantifying disease severity and is based on a simple numeric score derived from the CT scan. The interpretation of CT scan does not require radiology training and has a high inter-observer reliability.

The scoring system for the sinus groups is based on their appearances on the CT scan. Each group of sinuses (maxillary, frontal, sphenoid, anterior ethmoid and posterior ethmoid) on each side is judged on radiological images to be completely clear, partly opaque or completely opaque, scoring 0,1 and 2 points respectively. In addition, the degree of occlusion of the ostiomeatal complex in each side is judged as either not obstructed or obstructed, scoring 0 or 2 . In total six sites are scored in each side, and the total score is the sum of scores from each side and ranges from 0 to 24 , complete lucency of all sinuses to complete opacity of all sinuses (Table 6). 
Table 6: The scoring system of LMS

Anatomical site No abnormality Partial opacification Total opacification

Maxillary sinus

Right $\quad 0 \quad 1$

$\begin{array}{llll}\text { Left } & 0 & 1 & 2\end{array}$

Anterior ethmoid

Right $\quad 0 \quad 1 \quad 2$

$\begin{array}{llll}\text { Left } & 0 & 1 & 2\end{array}$

\section{Posterior ethmoid}

Left $\quad 0 \quad 1 \quad 2$

\section{Frontal sinus}

$\begin{array}{lll}\text { Right } & 0 & 1 \\ \text { Left } & 0 & 1\end{array}$

\section{Sphenoid sinus}

\begin{tabular}{llll|} 
Right & 0 & 1 & 2 \\
Left & 0 & 1 & 2 \\
\hline & & \\
\hline $\begin{array}{l}\text { Ostiomeatal } \\
\text { Complex }\end{array}$ & No obstruction & Obstructed \\
\hline Right & 0 & 2 \\
Left & 0 & 2 \\
\hline
\end{tabular}

Anatomically divided into 6 sites (Lund and Mackay 1993). Each side is graded separately. Radiological absence in all sites scores 0 and a maximum score of 24 is possible when all the anatomical sites are completely affected. In terms of ostiomeatal complex, grading according to opacity is not possible because of the size. Therefore obstruction versus not obstruction is used. Of note, an aplastic (absent) frontal sinus receives a score of 0 . All patients were diagnosed with chronic rhinosinusitis according to the definition of the European Position Paper on Rhinosinusitis and Nasal Polyps 2012 (Fokkens et al. 2012) as mentioned in the introduction. 
The LMS has been shown to correlate with disease severity, the extent of sinus surgery and has been identified as a strong predictor of symptom levels after treatment (patients with higher pre-op severity on CT show significantly higher improvement in symptom scores) (Brook et al. 2017). The LMS has been proved to be practical and accurate in several studies and was recommended by the Task Force on Rhinosinusitis for use as a diagnostic tool in everyday clinical practice as well as for research (Lund and Mackay 1993).

Based on the above recommendations we decided to use the LMS as it is currently the most accepted and widely used staging system, allowing comparison with other studies on CRS. In our study, CT scans of nasal sinuses were assessed independently by 2 physicians who are experienced in using LMS on CT scans (a radiologist who was blinded on the clinical presentation of the patient and an ENT surgeon). If there was a difference in the scoring of a CT scan between the two physicians, then the scan was discussed and a final consensus was reached.

\subsection{Asthma}

The presence of asthma was based on patient history revealing a diagnosis of asthma from a pulmonary physician or general practitioner and active prevention therapy with at least a beta- 2 agonist at the time of presentation in our ENT clinic.

\subsection{Surgery}

The decision to operate was always taken on an individual basis taking into account the patients symptoms and clinical signs. All patients were treated for a minimum of three months with topical steroids, nasal saline irrigation and in several cases of CRSwNP oral steroids prior to surgery, as advised by the European Position Paper on Rhinosinusitis and Nasal Polyps 2012 (Fokkens et al. 2012). Surgical interventions were carried out once the medical management was proven to be ineffective.

In all cases, FESS was performed aiming to restore sinus ventilation and remove foci of disease based on the concept of functional surgery of the nasal sinuses. The extent of surgery was based on the extent of sinus disease. The single steps encompass: uncinectomy with exposure and enlargement of the natural maxillary ostium, opening of the bulla ethmoidalis with access to the anterior and posterior ethmoid cells, improving the drainage pathway of the frontal sinus and dilatation of the access of the sphenoid sinus (Weber and Hosemann 2015).

In our study, we recorded the number of operations performed in allergic and non-allergic patients. We identified postoperative complications and divided them into major complications which required a surgical intervention and minor complications which did not require surgery and were managed conservatively or medically. 
We followed-up patients for 36 months after their initial operation and documented the need for a revision surgery due to recurrence of CRS.

\subsection{Ethical standards}

The study was approved by the University Hospital of Goettingen Ethics committee and was registered under the protocol number (DOK_88_2016 30062016, 12/7/16)

\subsection{Statistical Analysis}

For the following analysis the software STAT 14.1 (SAS; Cary, USA) was used and for the graphical representation the software Statistica 13.0 (TIBCO; Palo Alto, USA). Statistical analysis was performed using the Mann-Whitney test, two-sample t-test, chi-square test and Fisher's exact test where appropriate. A value of $\mathrm{p}<0.05$ was considered statistically significant. 


\section{Results}

938 consecutive patients were identified through electronic database searching who presented to our otorhinolaryngology clinic with rhinological symptoms within a four-year period (November 2012 to November 2016). 720 of these satisfied the inclusion criteria, and of these, 253 had a complete work-up including history taking, allergy testing, nasal endoscopy with 30-degree endoscope and a CT of the nasal sinuses available in electronic form in our database. Out of the 253, 195 patients satisfied the EPOS-2012 criteria for the diagnosis of CRS and were included in our study. The selection process is presented in Figure 1.

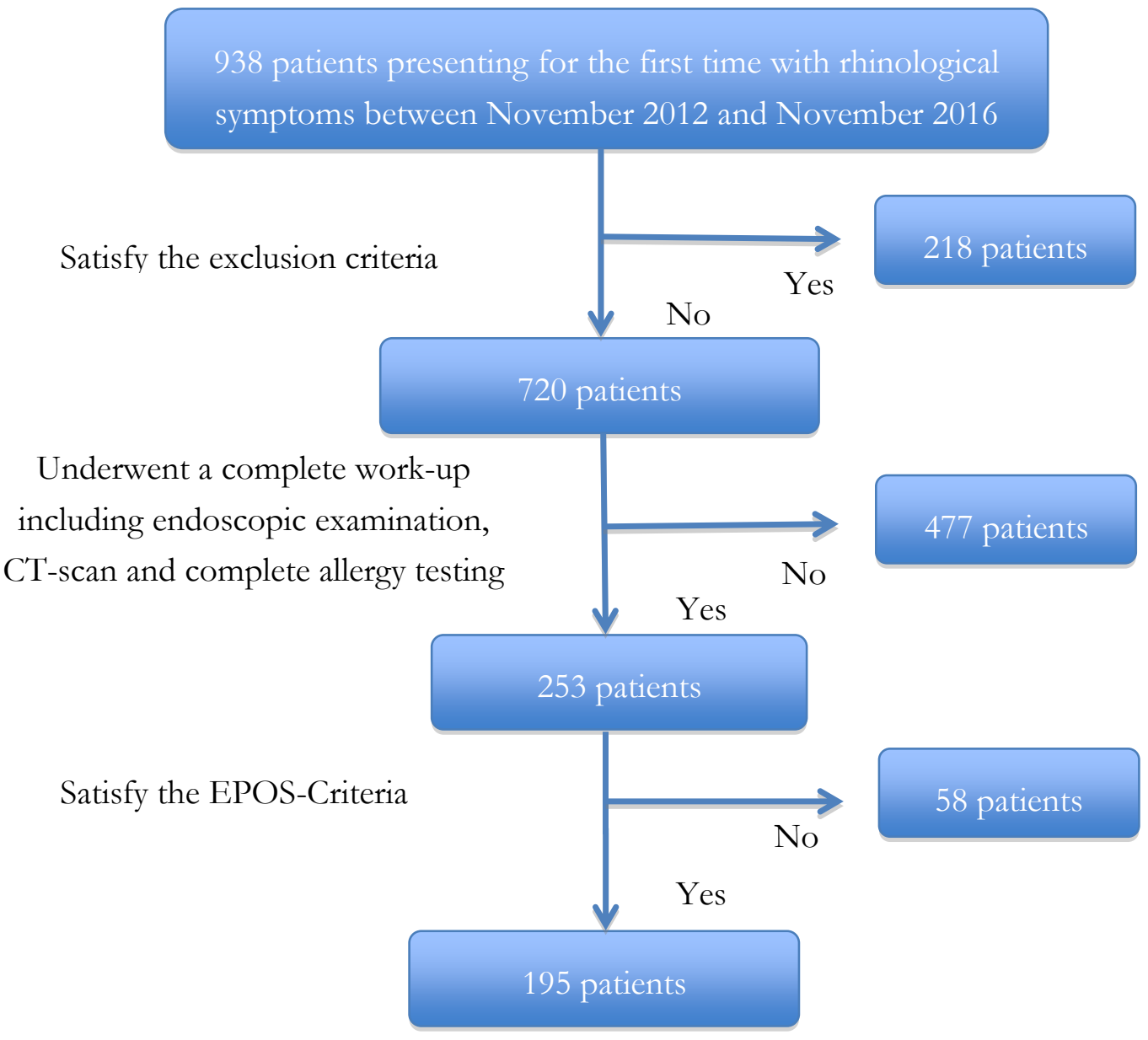

Figure 1: Flow diagram showing patient-selection. 938 consecutive patients who were referred to our clinic with rhinological symptoms between November 2012 and November 2016 were identified. After applying the inclusion and exclusion criteria, there were 195 patients who satisfied the EPOS-2012 criteria and were included in our study. 
These 195 patients included in our study were analyzed in two groups, patients with a chronic rhinosinusitis without evidence of an allergy and patients with chronic rhinosinusitis and a diagnosis of an allergy.

\subsection{Patients with CRS without evidence of an allergy}

There were a total of 115 patients with CRS without evidence of an allergy. 51 were female $(44 \%)$ and 64 male (56\%), with a mean age of 44.1 years (range: 18.0-79.1, SD: 16.66$)$. The mean LMS was 6.28 (SD: 5.69) for the whole group, 6.82 (SD: 6.48) for females and 5.84 (SD: 4.98) for males. 95 patients (82.6\%) had a diagnosis of CRSsNP and 20 of CRSwNP (17.4\%). 6 patients $(5.2 \%)$ had a diagnosis of asthma (Table 7$)$.

None of the above 115 patients was previously operated prior to the presentation in our clinic. Following our diagnostic procedures, 65 patients $(56.5 \%)$ were managed surgically with functional endoscopic sinus surgery and 60 medically with intranasal corticosteroids and daily saline irrigation.

Table 7: Demographics and LMS of the 195 patients included in our study

\begin{tabular}{|lcc|} 
& Patients with CRS & Patients with CRS \\
without allergy & 115 & and allergy \\
\hline Agtal Number & 44.1 (range 18.0-79.1) & 37.9 (range 18.2-79.8) \\
\hline Female & 51 & 35 \\
\hline Male & 64 & 45 \\
\hline Patients with CRSsNP & 95 & 55 \\
\hline Patients with CRSwNP & 20 & 25 \\
\hline LMS - total nos. patients & 6.28 & 7.46 \\
\hline LMS Female & 6.82 & 6.74 \\
\hline LMS Male & 5.84 & 8.02 \\
\hline Presence of asthma & 6 & 18 \\
\hline
\end{tabular}




\subsection{Patients with CRS and diagnosis of allergy}

There were a total of 80 patients with CRS and a diagnosis of an allergy. 35 were female $(43.8 \%)$ and 45 male (56.3\%), with a mean age of 37.9 years (range: 18.2-79.8, SD: 14.63). The mean LMS was 7.46 (SD: 6.28) for the whole group, 6.74 (SD: 5.60) for females and 8.02 (SD: 6.77) for males. 55 patients (68.8\%) had a diagnosis of CRSsNP and 25 of CRSwNP (31.3\%). 18 patients $(22.5 \%)$ had a diagnosis of asthma.

44 patients (55\%) had a single allergy: $19(23.8 \%)$ to house dust mite, $16(20 \%)$ to pollen of early blossoming plants, $7(8.8 \%)$ to pollen of grass or rye, $1(1.3 \%)$ to dog dander and 1 $(1.3 \%)$ to ragweed pollen. 36 patients $(45 \%)$ had multiple allergies: $19(23.8 \%)$ to both pollen and house dust mite, $10(12.5 \%)$ to early and late blossoming pollen, $3(3.8 \%)$ to both house dust mite and animal dander, $3(3.8 \%)$ to early and late blossoming pollen, mite, fungi and animal dander and $1(1.3 \%)$ to house dust mite and mold.

When dividing the total number of 80 allergic patients into "seasonal allergy", "perennial allergy" and "mixed allergy", $34(42.5 \%)$ had a seasonal allergy, $24(30 \%)$ had a perennial allergy and $22(27.5 \%)$ had a mixed allergy. After the diagnosis of allergy, 14 patients $(17.5 \%)$ opted for allergen immunotherapy.

None of the above 80 patients was previously operated prior to the presentation in our clinic. Following our diagnostic procedures, 52 patients (65\%) were treated surgically; the rest did not undergo a surgical procedure.

\subsection{Statistical analysis}

We statistically analyzed several factors and parameters:

\subsubsection{Presence/absence of allergy and LMS in all patients}

We tested whether the presence or absence of an allergy had an effect on the LMS in all 195 patients that were included in our study. There were 115 patients with CRS without an allergy and 80 patients with CRS with a diagnosis of allergy (Table 7). The mean LMS in the group without allergy was 6.28 and 7.46 in the group with a diagnosed allergy. Although the LMS was higher in the latter group, there was no statistical difference in the LMS when comparing the two groups ( $\mathrm{p}$-value $=0.23$, Mann-Whitney test) (Figure 2). 


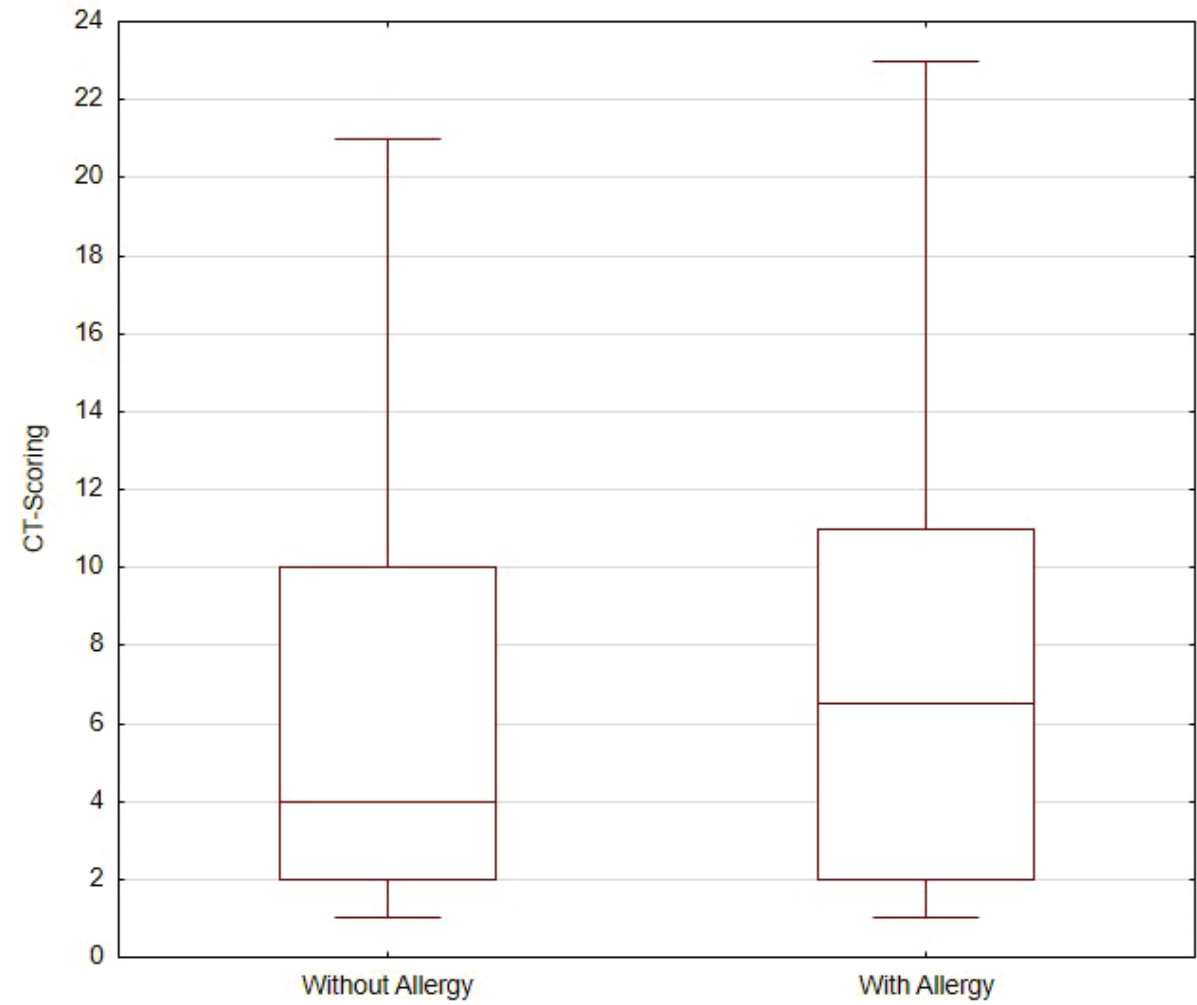

Figure 2: Comparison of LMS in 115 patients with CRS without an allergy and 80 patients with CRS and an allergy. There was no statistical difference in the LMS between the two groups.

\subsubsection{Presence/absence of allergy and LMS in patients with severe CRS}

To further investigate this relationship, we analyzed only patients with a severe CRS with a LMS of 10-24. This division into mild (LMS 1-3), moderate (LMS 4-9) and severe CRS (LMS 10-24) was based on previous studies by Bhattacharyya and Fried (2003) who assessed the diagnostic accuracy of the LMS. A total of 60 patients were included. 33 patients hat CRSwNP and 27 patients CRSsNP. 33 patients (55\%) had no allergy, 18 (30\%) were male and $15(25 \%)$ were female. The mean age was 46.9 years (SD: 15.8$)$ and the mean LMS was 13.96 (SD: 4.13).

$27(45 \%)$ patients had an allergy, $18(30 \%)$ were male and $9(15 \%)$ were female. The mean age was 40.03 (SD: 16.86) and the mean LMS was 14.74 (SD: 4.67)

Similar to the first analysis that included all patients, in this patient subgroup with severe CRS, the presence of allergy did not significantly affect the severity of LMS ( $\mathrm{p}$-value = 0.58, Mann-Whitney test) (Figure 3). 


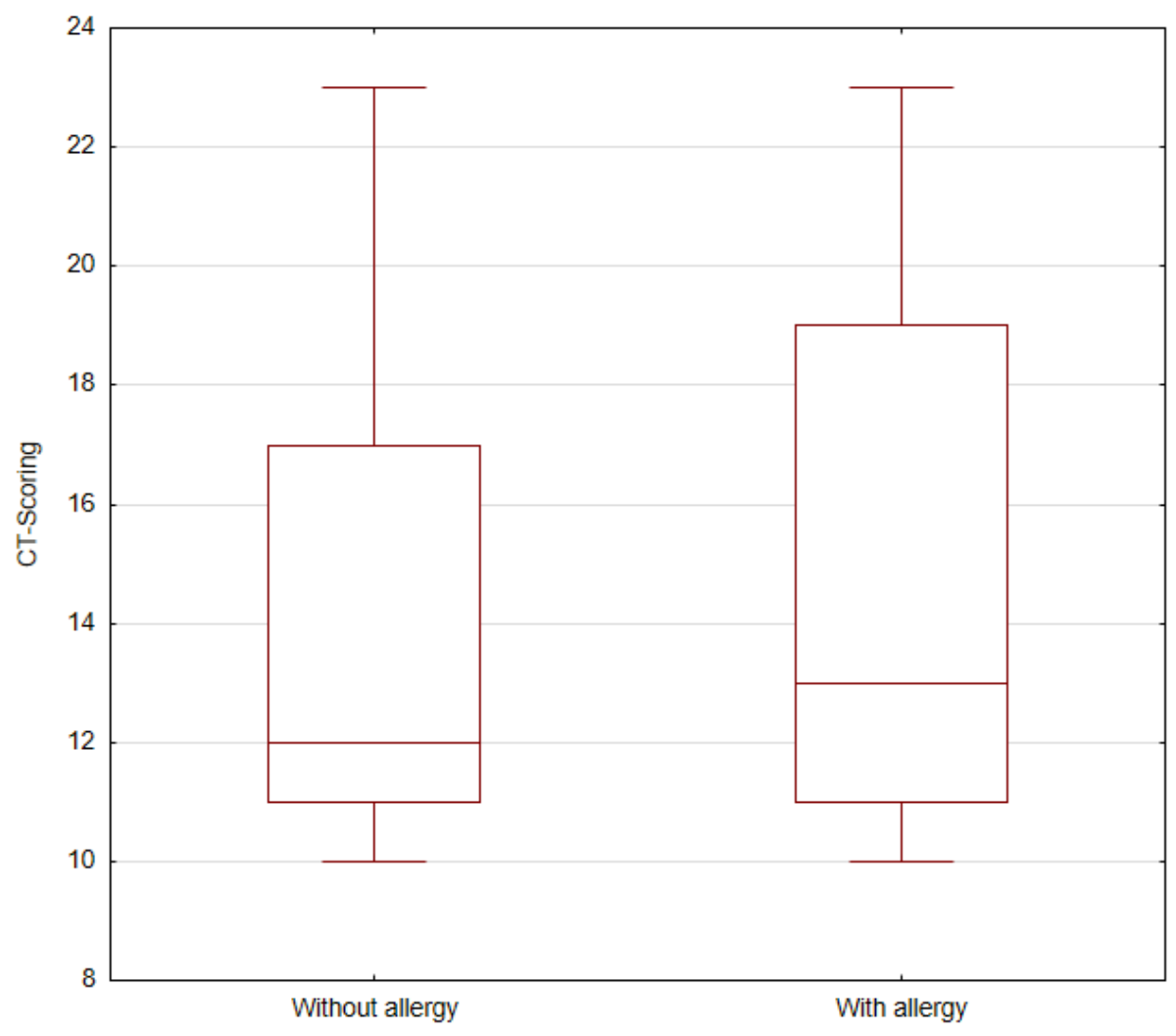

Figure 3: Comparison of LMS in 60 patients with severe CRS. 33 patients had severe CRS without an allergy and 27 with an allergy. There was no statistical difference in the LMS between the two groups.

\subsubsection{Presence/absence of allergy and LMS in patients with CRSwNP}

We next tested whether the presence or absence of allergy affects the CT-score in patients with chronic rhinosinusitis and nasal polyps (CRSwNP). There were a total of 45 patients, $24(53 \%)$ were male and 21 were $(47 \%)$ female. The mean age of these patients was 42.4 years and the mean LMS was 13.77 (SD 6.15). Within this group, 25 (56\%) patients had an allergy, $15(33.3 \%)$ were male and $10(22.2 \%)$ were female. The mean LMS was 13.64 (SD: 6.30). 20 patients had no allergy. $11(24.4 \%)$ patients were female and $9(20 \%)$ were male. The mean LMS was 13.95 (SD: 6.12).

We tested whether there is a statistical significant difference in the LMS of patients with CRSwNP without allergy and CRSwNP and allergy. There was no statistical significance in the LMS when comparing the two groups of patients with nasal polyps ( $\mathrm{p}$-value $=0.87$, two-sample t-test) (See Figure 4). 


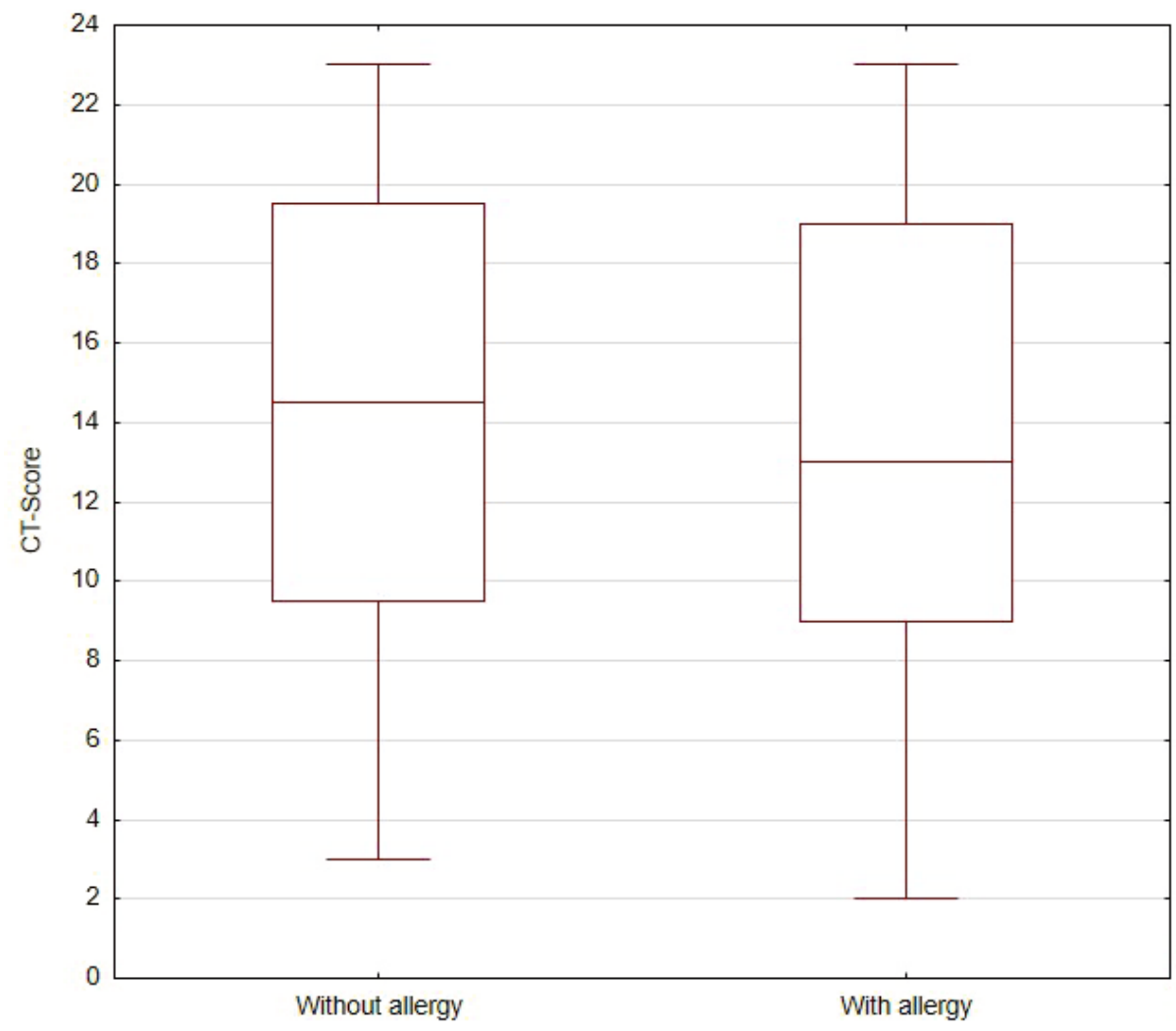

Figure 4: Comparison of LMS in 45 patients with CRSwNP. 20 patients did not have an allergy and 25 had a diagnosis of an allergy. There was no statistical difference in the LMS between the two groups.

\subsubsection{Presence/absence of asthma and LMS in all patients}

We analyzed whether the presence of asthma affects the LMS. 24 patients with a diagnosis of asthma were identified within the total population of patients. Mean age was 41.5 years (SD: 16.80$) .18$ patients $(75 \%)$ were allergic and only 6 patients $(25 \%)$ had no diagnosed allergy. 13 patients (54.1\%) were female and $11(45.9 \%)$ were male. Patients with a diagnosis of asthma had a higher LMS (mean: 9.92, SD: 8.10) than patients without (mean: 6.82, SD: 5.48). However, the difference was not statistically significant ( $\mathrm{p}$-value $=0.06$, Mann-Whitney test) (Figure 5). 


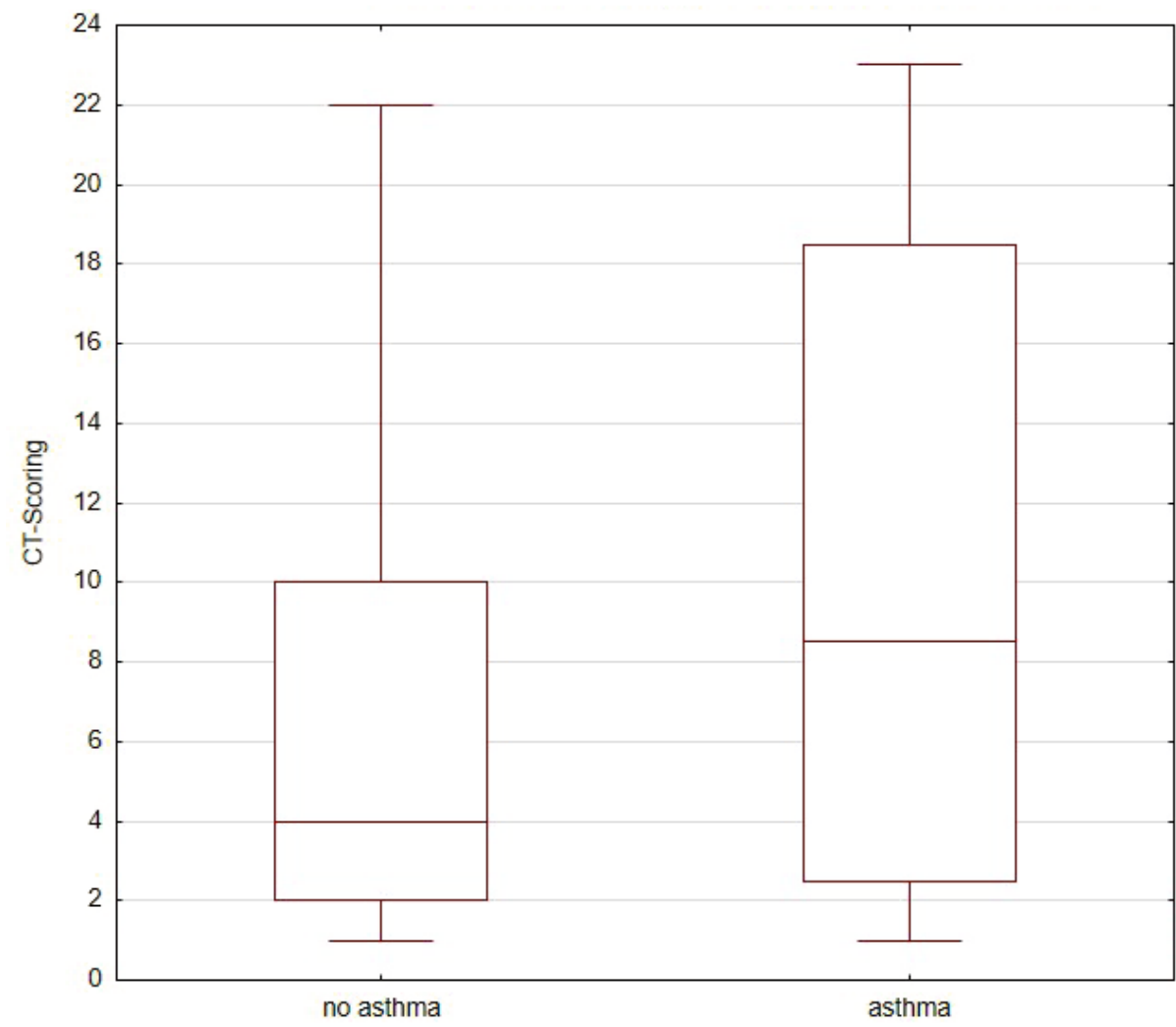

Figure 5: Comparison of LMS in 171 patients with CRS without asthma and 24 patients with CRS and a diagnosis of asthma. There was no statistical difference in the LMS between the two groups.

\subsubsection{Effect of gender on the LMS}

We statistically analyzed whether gender affected the LMS in all patients with CRS (CRSsNP and CRSwNP, allergic and non allergic).

There were 109 male patients with a mean age of 42.33 (SD: 16.45). The mean LMS was 6.74 (SD: 5.86). There were 86 female patients with a mean age of 40.63 (SD: 15.72). The mean LMS was 6.79 (SD: 6.11). There was no statistical significance in the LMS between male and female patients ( $\mathrm{p}$-value $=0.99$, Mann-Whitney test) (Figure 6). 


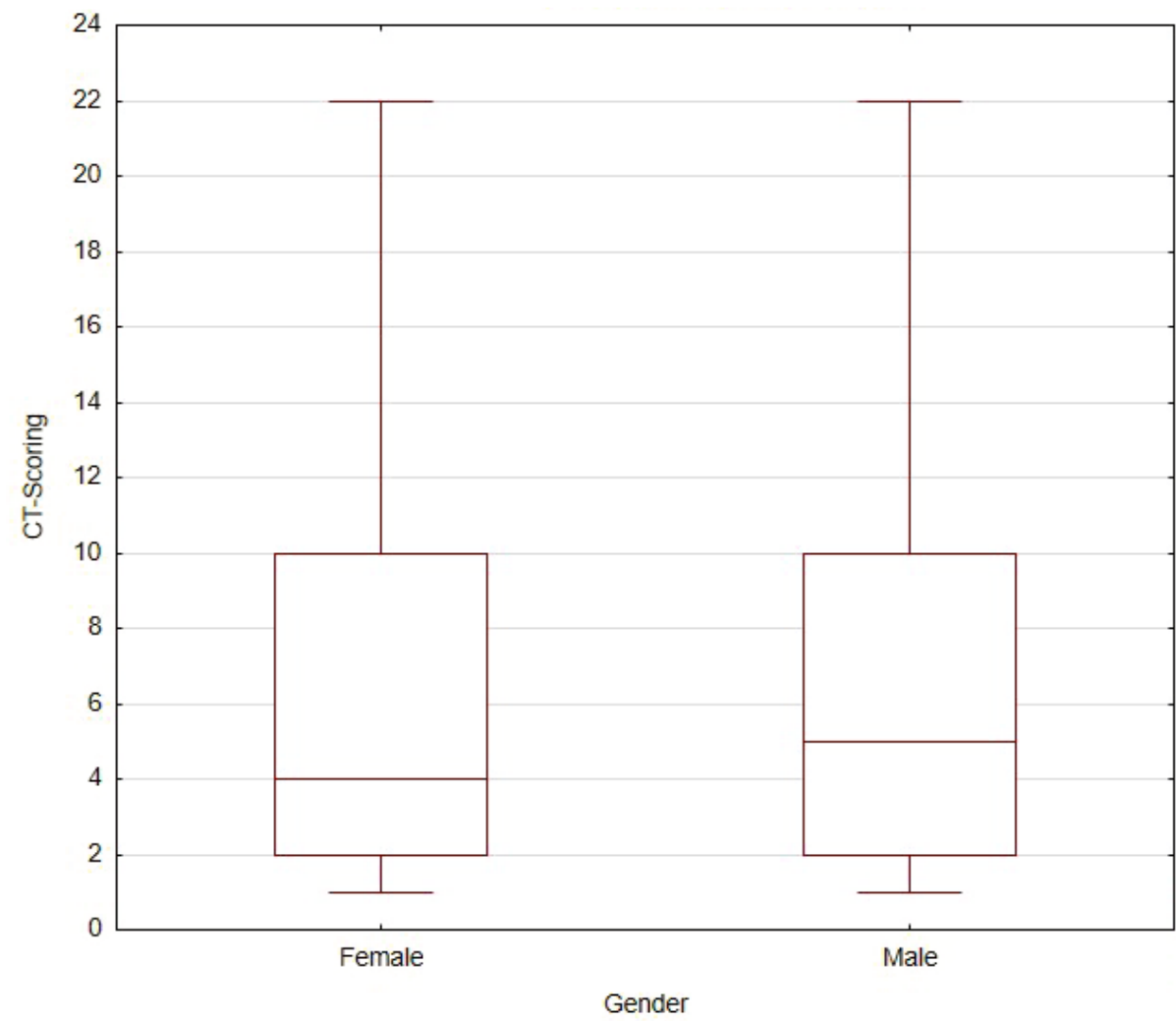

Figure 6: Comparison of LMS between gender. There were 109 male and 86 female patients. There was no statistical difference in the LMS between the two groups.

\subsubsection{Type of allergy and the effect on LMS}

We tested whether the type of allergy affects the radiological severity of CRS. We divided the 80 patients with recorded allergies into three groups based on the type of allergy they were diagnosed with: seasonal allergy, perennial allergy and mixed allergy (both seasonal and perennial).

34 patients $(42.5 \%)$ had a seasonal allergy with either early tree or grass pollen. Within this group 20 patients were male and 14 were female. The mean LMS was 6.44 (SD: 5.19).

24 patients $(30 \%)$ had a perennial allergy with house dust mite, mold or dog/cat dander. 17 patients were male and 7 were female. The mean LMS was 8.63 (SD: 6.87).

22 patients $(27.5 \%)$ had a mixed allergy. 14 patients were female and 8 were male. The mean LMS was 7.77 (SD: 7.15).

There was no statistically significant difference in the LMS when dividing patients with allergy in three different groups (seasonal, perennial and mixed) ( $\mathrm{p}$-value $=0.59$, KruskalWallis test) (Figure 7). 


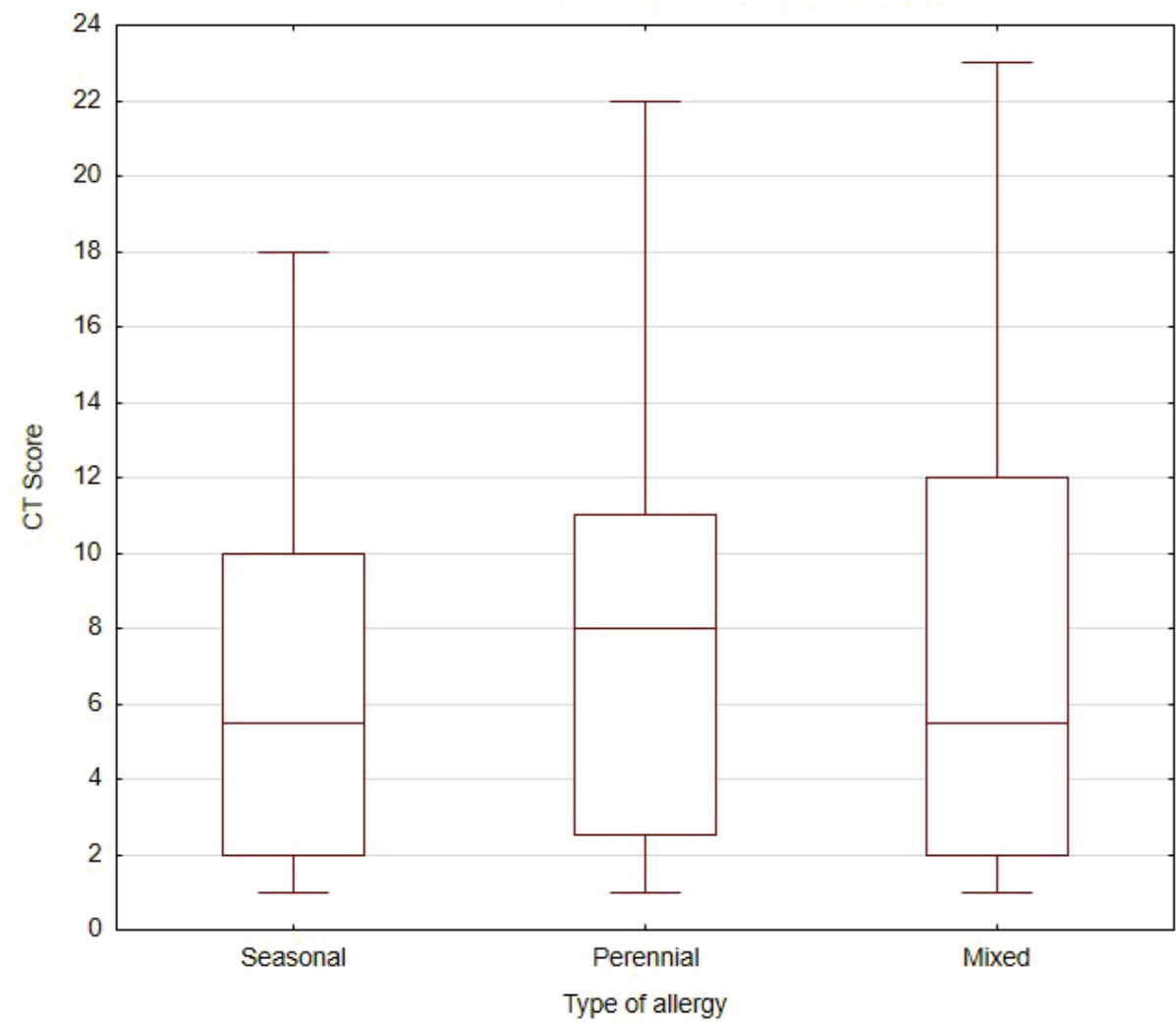

Figure 7: Comparison of LMS of 80 patients with CRS and allergy according to the three different allergy groups (seasonal, perennial and mixed). There was no statistical difference in the LMS between the three groups.

\subsubsection{Asthma and the presence of allergy}

We examined the relationship between asthma and the presence of allergy and compared it to our non-allergic patients. There was a positive association between allergy and asthma (p-value $<0.001$, chi-square test). Using the odds ratio test a value of 5.27 was calculated. This indicates that an allergic patient is 5.27 times more likely to have asthma than a patient with no allergy.

\subsubsection{LMS in the presence of perennial allergy compared to non-allergic patients}

We investigated whether the presence of perennial allergy, which has previously been shown to impact CRS more than any other type of allergy, affects the LMS. 24 patients with only a perennial allergy were identified (Mean LMS: 8.63, SD: 6.87) and were compared to all non-allergic patients ( $\mathrm{n}=115$, LMS: 6.28, SD: 5.69). There was no 
statistically significant difference in the LMS between patients with no allergy and those with perennial allergy ( $p$-value $=0.13$, Mann-Whitney test).

\subsubsection{The effect of allergy on postoperative complications}

65 patients $(56.5 \%)$ of the total group of non-allergic patients were operated. There were 4 major complications that required revision surgery; 3 patients had postoperative bleeding and 1 patient had a skull base defect. There were 9 minor complications; 2 patients had mild postoperative bleeding and 7 patients had postoperative infections, which were treated medically/conservatively.

52 patients $(65 \%)$ of the total group of allergic patients were treated surgically. There were 3 major complications that required revision surgery; all patients had postoperative bleeding. There were 6 minor complications; 2 patients had mild postoperative bleeding and 4 patients had postoperative infections, which were treated medically/conservatively. No statistically significant relationship between allergy and the presence of postoperative was identified (major complications, $\mathrm{p}$-value $=0.46$, chi-square test) (minor complications, $\mathrm{p}$-value $=0.37$, chi-square test).

\subsubsection{The effect of allergy on the need for a revision surgery}

Within 36 months after the operation, 9 patients out of the 52 patients with allergies $(17.3 \%)$ required a revision surgery because of recurrent disease. In comparison to the above, only 4 out of the 65 non-allergic patients $(6.2 \%)$ required revision surgery within the same time frame. We found that there is a statistically significant association between allergy and revision surgery ( $\mathrm{p}$-value $=0.03$, chi-square test). Using the odds ratio test a value of 3.52 was calculated. This indicates that a patient with an allergy is 3.52 times more likely to have revision surgery than a patient with no allergy.

\subsubsection{The relationship between CRSwNP and asthma}

45 patients with CRSwNP were identified. 11 patients had a diagnosis of asthma. Within the group of 150 patients with CRSsNP only 13 patients had a diagnosis of asthma. Statistical analysis showed that the presence of polyposis significantly affected the presence of asthma ( $p$-value $=0.005$, chi-square test). To quantify the association, we used the odds ratio test and we found that a patient with polyposis is 3.41 times more likely to have asthma than a patient without polyposis. 


\subsubsection{The relationship between mean age at first presentation and mean age at first operation between the two groups}

We compared the mean age of the 115 patients without an allergy (44.1 years, SD: 16.70), with the 80 patients with an allergy (37.9 years, SD: 14.63). Statistical analysis showed a significant difference of the mean age of the two groups ( $\mathrm{p}$-value $=0.009$, $\mathrm{t}$-test). In our study, patients with an allergy were 7.2 years younger when presenting for the first time to our clinic with symptoms compared to patients without an allergy.

A similar relationship was identified when comparing the mean age of patients who were operated between the two groups. The mean age at first operation for patients without an allergy was 42.2 years (SD: 14.62) and for those with an allergy was 37.5 years (SD: 14.55). This reveals that patients with an allergy were operated 4.7 years younger compared to those without an allergy. Statistical analysis showed a significant difference of the mean age of the two groups ( $\mathrm{p}$-value $=0.036$, $\mathrm{t}$-test) . 


\section{Discussion}

We are interested in the complex interplay between CRS and allergy. Our study aims to improve the understanding of the relative roles of perennial and seasonal allergens in chronic rhinosinusitis. We investigated 195 patients with CRS who were not previously operated and assessed whether the severity of their disease measured radiologically using the LMS was affected by various factors such as allergy, gender and the presence of asthma. In addition, we evaluated whether the presence of allergic rhinitis has an influence on the age of presentation, age of operation, the rate of complications and need for revision surgery.

Patients with an allergy had a tendency to more severe CRS when measured radiologically by the LMS. However, this difference was not statistically significant. There was no statistically significant difference in the LMS when comparing patients with and without asthma. We also failed to find an association between gender and LMS. The type of allergic rhinitis did not appear to have a significant effect on the LMS. There was also no statistically significant relationship between allergic rhinitis and the presence of postoperative complications. In our study patients with an allergy presented earlier and received a FESS significantly younger than patients without an allergy. In addition, we found a positive association between the presence of allergic rhinitis and the necessity of a revision surgery.

CRS is thought to begin with a transition from acute rhinosinusitis or rhinitis, which under recurrent insults in genetically susceptible individuals progresses to CRS. From then on, this state can evolve from periods of remission followed by relapse into the symptomatic state, characterized by persistent symptoms. The frequency, evolution rates and risk factors that promote such a transition have yet to be identified, but this theory may be used to explain the natural history of the various clinical phenotypes of CRS (Tan et al. 2013b).

We hypothesized that allergy could be a driving force influencing this progression into CRS. We assumed that the repeated exposure to allergens reduces the threshold of response of the mucosa to other stimuli, increasing mucosal edema, unleashing an inflammatory cascade and promoting the transition to a chronic inflammatory state.

Unlike CRS, atopy to respiratory allergens is directly implicated in the pathophysiology of other chronic inflammatory conditions of the airway tract such as asthma (Burrows et al. 1989). Our results have also supported this association. In our study there was a positive association between allergy and asthma with allergic patients being 5.27 times more likely to have asthma than patients with no allergies.

In terms of CRS the role of allergy is still controversial with contrasting results reported in studies during the last 20 years. 


\subsection{Evidence of a positive relation between allergy and CRS}

Several studies have reported much higher rates of sensitization to one or more perennial aeroallergens compared to our study, particularly dust mites in patients with CRS. Friedman (1975) demonstrated that $94 \%$ of adult patients who had undergone a sphenoethmoidektomy due to CRS were atopic.

Unlike our results, which showed no significant relationship between the presence of allergic rhinitis and severity of CRS, several studies have identified a positive association between atopy and disease severity graded on CT scans. In 199 patients with CRS requiring FESS, the mean CT score of nasal sinuses using the LMS was significantly higher in the atopic patients than in non-atopic patients overall $(14.2+/-1.6$ versus $12.2+/-1.3$; p-value = 0.05), although within each clinical subdivision, no statistically significant relationship was detected between a patients' atopic status and their LMS (Robinson et al. 2006).

Krouse et al. (2000) showed a significant correlation between CT score using the LMS system and sensitivity to allergens using the skin end point titration in 48 patients with chronic rhinosinusitis. Emanuel and Shah (2000) reported that the majority of patients (84\%) presenting with persistent CRS requiring surgical treatment tested positive for allergies. These patients had evidence of disease on CT imaging. However, an interesting finding was the relatively lower percentage of allergy $69 \%$ in the group of patients with the most severe disease, compared to $83 \%$ and $88 \%$ respectively in the groups of patients with the mildest form of sinus disease on CT scans. $58 \%$ had multiple allergen sensitivities, and $26 \%$ had sensitivity to a single allergen. There was a clear preponderance of perennial allergy reactivity over seasonal allergens in these patients with dust mite being the most common allergen (82\%) amongst the group with single allergen sensitivity. In this study the type and degree of sensitivity of the allergen did not impact significantly on the grade of sinus disease severity based on CT scan opacification.

Ramadan et al. (1999) published results from 42 patients with no prior surgical treatment presenting with symptoms of CRS. Allergic patients were found to have a higher LMS (mean score $=12$ ) when compared to non-allergic patients (mean score $=6$ ). A positive association between the presence of inhalant allergy and a statistically significant increase in the Lund Mackay score was shown by Batra et al. (2013) in 225 patients undergoing revision surgery for refractory chronic rhinosinusitis with/without polyps. In their study, the overall prevalence of inhalant allergy was $38.7 \%$ - a value much lower than similar studies.

In another study by Houser and Keen (2008), a high prevalence of atopy (56,4\%) was reported in a cohort of patients refractory to medical treatment undergoing surgery due to CRS, particularly perennial allergens. Their results indicated a significantly higher 
prevalence of atopy amongst these patients compared to the general population (Bellanti and Wallerstedt 2000). However this study included patients with positive allergy testing without taking into account any clinical symptoms and relevant history suggesting allergy. In contrast, our study aimed to overcome this limitation and inconsistency shown by previous studies. We identified individuals as 'allergic' only when they had a history suggesting allergy, combined with a positive skin prick test and specific $\operatorname{IgE}$ and in several cases nasal provocation to differentiate patients with perennial allergies from those with CRS.

Similar findings to Houser and Keen, with a very high incidence of sensitization to perennial allergens but not to seasonal allergens were reported in several other studies. Amongst 48 patients with CRS unresponsive to medical therapy that required surgical treatment, $57.4 \%$ had a positive allergy test (atopy), with the vast majority of $92 \%$ having sensitivity to one or more perennial allergens-most frequently, molds and dust mites (Gutman et al. 2004). Berrettini et al. (1999) compared the CT scans of 40 adult patients with perennial allergic rhinitis to 30 control subjects and found significantly higher incidence of sinusitis in the allergic group compared to the control group $67.5 \%$ versus $33.4 \%$ ). In our study, we specifically investigated whether the different type of allergy and particularly perennial allergy has an effect on the LMS. Within a group of 80 allergic patients, 24 had only a perennial allergy. The LMS of these patients was higher (8.63 compared to 6.44 in the group of patients with seasonal allergies and 7.77 in the group with mixed allergies), however, there was no statistically significant difference in the LMS when comparing the three different groups (seasonal, perennial and mixed).

The majority of authors from the above studies indicate that the high prevalence of atopy/allergy is thought to be a causative factor for CRS, as the constant inflammation in the nasal sinuses caused by (perennial) allergy leads a vicious cycle of poor mucociliary clearance, obstruction of the sinus ostia and thus development of CRS (Houser and Keen 2008). Our study failed to show similar results which makes us wonder whether this a true representation or whether it is the result of a selection bias in several studies because of physicians who are interested in allergy. 


\subsection{Support that allergy plays a role in CRSwNP and not in CRSsNP}

Some studies have shown a positive association between allergy and CRSwNP but not with CRSsNP. Asero et al. (2001) showed a 63\% prevalence of positive skin prick test (but not significant history of allergy) in patients with nasal polyposis. The role of perennial respiratory allergens on CRSwNP was also investigated in the following study by Grigoreas et al. (2002). They showed that there was an increased frequency of CRSwNP in patients with a perennial respiratory allergy (rhinitis, asthma).

We also examined whether the presence or absence of allergy affects the CT-score in patients with chronic rhinosinusitis and nasal polyps (CRSwNP). Unlike the above studies, we did not find a statistically significant relationship between LMS and the presence of CRSwNP. Comparable to our results Li et al. (2016) identified no association between atopy status and LMS in a prospective study involving 210 patients with CRSwNP.

\subsection{Evidence of no association between allergy and CRS severity}

In our study, the mean LMS of patients with an allergy was higher compared to the LMS of patients without an allergy (7.46 vs 6.28). After our statistical analysis between the two groups we failed to find a significant association between the presence of allergy and the severity of CRS measured radiologically by the LMS. The same was true when comparing patients with severe CRS. Similar results were identified by various authors in the past.

Settipane and Chafee (1977) found a negative correlation between allergy and CRSwNP. In their study the most severe polyposis was identified in patients with a negative skin prick test. However, at the time no CT diagnostic evaluation of the sinuses was performed and the assessment of polyposis was made only on clinical examination. In a study of 2,200 Italian children evaluated for chronic respiratory symptoms, sensitization to at least one inhalant allergen by skin test and detection of high total $\operatorname{IgE}$ was $29.9 \%$, with no positive association between aeroallergen sensitization and chronic sinusitis. Authors concluded that the prevalence of sensitization to respiratory allergens in children with chronic sinusitis is comparable with that of the general pediatric population (Leo et al. 2007).

Tan et al. (2011) reviewed 125 patients failing medical therapy for CRS and found no significant correlation between atopy and LMS, or the influence of sensitivity to any single allergen on CRS disease severity. $82.4 \%$ of these patients were identified as atopic, a rate much higher compared with the general population. The authors of the above study suggested that these high rates of atopy, which were also observed in other studies of similar design, were due to referral patterns and referral biases resulting in an overrepresentation of allergic patients. 
Pearlman et al. (2009) investigated the relationship between the severity of CRS measured by the LMS and found no statistical relationship between LMS and atopic status in the entire group.

A study published in 2017, which is one of the biggest studies up to date with 437 patients with CRS, failed to show a positive association between atopy and CRS in patients with allergic sensitization. The mean LMS did not significantly differ between 251 patients with a positive in vitro allergen test and 186 patients with a negative test (Brook et al. 2017). The two most recent studies by Hamizan et al. (2018) and Shen et al. (2019) which compared patients with CRS with and without allergies also failed to identify a positive correlation between allergy and LMS. Hamizan et al. investigated the central radiological pattern of mucosal disease in patients with inhalant allergen sensitization and found no statistically significant difference in the LMS between 49 non-atopic patients and 63 allergen-sensitized patients. However, they reported that the central radiological pattern of mucosal disease in all the paranasal sinuses was statistically associated with inhalant allergen sensitization. Shen et al. (2019) investigated 138 CRS patients who underwent endoscopic sinus surgery and showed that the LMS was not significantly different between the allergic and non-allergic group.

\subsection{Association between allergy and revision surgery}

In our study we found a positive association between allergy and the need for revision surgery. Similar results were published in several other studies. In a large study, which included 29,934 patients with a mean length of follow-up of 9.7 years after a FESS, the long-term revision rate was found to be $15.9 \%$. Amongst other factors which included nasal polyps, comorbid asthma, and female gender, allergy was also identified as a significant factor increasing the risk of revision surgery (Smith et al. 2019).

Calus et al. (2019) showed that allergic sensitization is a significant risk factor predicting the need for revision surgery in a long-term prospective study which included patients with CRSwNP with a follow-up time of 12 years. Comparable results have been shown in the pediatric population. In a retrospective review by Wu et al. (2020) nasal allergy was identified as significant risk factor for revision surgery.

This relationship has not been identified in various other publications. Batra et al. (2013) investigated 225 patients with refractory chronic rhinosinusitis and indicated a higher disease burden linked with allergic rhinitis, but no higher risk of revision surgery. 


\subsection{Association between allergy and asthma}

We analyzed the relationship between asthma and the presence of allergy in our study and compared it to our non-allergic patients. There was a statistically significant positive association between allergy and asthma. Within our cohort, a patient with allergic rhinitis is 5.3 times more likely to have asthma than a patient with no allergy. This is consistent with published literature in the last 20 years from large epidemiological studies indicating that allergic rhinitis is one of the most significant risk factors for the development of asthma (Annesi-Maesano 1999; Tan et al. 2013b). We are currently aware that the respiratory tract is a single continuous functional entity with common pathological mechanisms acting in the nose/nasal sinuses and in the bronchi.

\subsection{Association between CRSwNP and asthma}

Similar to the above findings, our study identified a statistically significant relationship between CRSwNP and the presence of asthma. In our study, a patient with nasal polyps is 3.4 times more likely to have asthma than a patient without. This has been documented in the past with studies confirming the prevalence of asthma in up to $48 \%$ of patients with CRSwNP in comparison to $16 \%$ in patients with CRSsNP (Promsopa et al. 2016).

\subsection{Association between allergy and postoperative complications}

Analysis of major and minor postoperative complications in our patients undergoing functional endoscopic sinus surgery did not identify a significant association between allergy and the risk of developing postoperative complications. This has been previously investigated and reported similarly by other authors. Chou et al. (2016) reported 7.8\% of postoperative complications in 997 patients, which is in line with our results. They identified high polyp grading (Grades 2 and 3), inexperienced surgeon and the use of powered instruments as risk factors for the development of complications. Asaka et al. (2012) identified Asthma and CRSwNP as risk factors. In their study, patients with an allergy did not appear to have a statistically significant higher risk for the development of postoperative complications.

\subsection{Revision surgery}

The rate of revision surgery after functional endoscopic sinus surgery can range according to the population under study, the subtype of CRS and the follow-up time. However, in a 
large prospective cohort study, with 1459 patients followed-up for 5 years, the rate of revision surgery approached 20\% (Hopkins et al. 2009). In our investigation, within 36 months of follow-up, we recorded in total $11.1 \%$ revision rate. Revision surgery was required in $17.3 \%$ of patients with an allergy compared to $6.2 \%$ of patients without an allergy. Analysis of the above results showed a statistically significant relationship between allergy and the need for revision surgery.

In the past, controversial results have been published regarding the role of allergy on the rate of revision surgery, with the majority of authors finding no significant association between allergy and the need for revision surgery. Robinson et al. (2006) reported no significant difference in the rate of revision surgery between atopic and non-atopic patients in a prospective study that included 193 consecutive patients with CRS. Koskinen et al. (2016) followed 178 patients retrospectively for 5 years and identified allergic rhinitis as a significant factor associated with the need for revision surgery.

\subsection{Age at first presentation, first operation and disease progression}

We analyzed whether allergy has an influence on the age of patients seeking medical treatment at our tertiary otorhinolaryngology center. Our findings indicated that patients with an allergy were 7.2 years younger $(37.9$, SD: 14.63$)$ at the time of first presentation compared to patients without an allergy (44.1 years, SD: 16.70). We also compared the mean age of patients who were operated between the two groups. We found that patients with an allergy were operated on average 4.7 years younger (37.5, SD: 14.55$)$ compared to those without an allergy (42.2 years, SD: 14.62).

A similar finding was reported by Shen et al. (2019) who reported that the mean age of those receiving endoscopic sinus surgery was 7 years younger in the allergic, compared to the non-allergic group $(42.8 \pm 15.3$ years versus $49.8 \pm 15.8$ years, $p$-value $=0.008)$. Similar to our study, the LMS scores were not significantly different between the two groups. However, in this study from Taiwan, $90 \%$ of patients had allergies to house dust mites and none had allergies to grass/pollen, something unusual and by no means similar to the distribution of allergies within our cohort.

Based on their results, Shen et al. (2019) have indicated that allergy may accelerate disease progression in CRS. To date there have been no other studies indicating such a relationship between the presence of allergy and the earlier onset of symptoms and need for a surgical intervention. It is difficult to ascertain whether allergy truly accelerates disease progression or whether it results from a tendency of patients with allergies to consult doctors earlier. 


\subsection{Allergy, atopy and inconsistencies in previous studies}

The terms "atopy" and "allergy" are often used inconsistently in scientific literature especially in studies of allergic rhinitis. Studies have often included patients with atopy or just sensitized patients based on a skin prick test or specific $\operatorname{IgE}$ detection, without taking into account the clinical symptoms or performing a nasal provocation test. Many published reports have therefore assessed the relationship between atopy and chronic rhinosinusitis rather than allergic rhinitis.

Our study is one of the few studies to compare severity of CRS based on the LMS in patients with a diagnosed allergy based on thorough allergy investigations, to patients with no allergy. All our patients have been identified as "allergic" only after having a positive history of allergic rhinitis, having a positive skin prick test, detection of specific $\operatorname{IgE}$ and in 23 patients also performing a nasal provocation test.

Previous studies have included patients as allergic after having only a positive in vitro allergen test (Ramadan et al. 1999; Robinson et al. 2006; Brook et al. 2017), with just a positive skin prick test (Berrettini et al. 1999; Pearlman et al. 2009), with either in vitro testing or skin prick test (Emanuel und Shah 2000; Batra et al. 2013; Hamizan et al. 2018), with only skin end-point titration test (Krouse 2000), with in vitro testing or skin end-point titration (Gutman et al. 2004), with a mixture of skin prick tests, intradermal dilutional test und in vitro test (Houser and Keen 2008). Only one study (Tan et al. 2011) included patients with a positive history, evaluated them using standard skin prick test and intradermal testing when skin prick was negative. Therefore, many of the above patients which have been included in the above studies are by definition atopic/sensitized to allergens but not allergic. We also conducted one of the few studies to include patients only if they satisfied the EPOS 2012 criteria for CRS, thus standardizing the selection of patients. 


\subsection{Possible mechanism - local inflammatory pathway}

One might wonder why allergy, which impairs normal sinus physiology and promotes inflammation, does not predispose or exacerbate CRS in an obvious way. A number of authors have suggested that CRS is an inflammatory disease that occurs independently of systemic IgE-mediated pathways. Significant levels of mucosal IgE, eosinophils and Th2 cytokines have also been shown to be present in nonatopic patients (Carney et al. 2006).

In addition, authors have identified patients with persistent sinonasal symptoms, negative skin prick tests and positive nasal provocation tests with raised local production of $\operatorname{IgE}$ antibodies (Rondón et al. 2007). There is evidence that elevated levels of local $\operatorname{IgE}$ and activation of mast cells and eosinophils in nonatopic patients occurs directly by local microorganisms without allergy being the direct causative agent (Terzakis and Georgalas 2017). The possible explanation for this to occur is $\operatorname{IgE}$ formation induced by superantigens including staphylococcal enterotoxins A and B. These mucosally formed IgE are functional, even in the absence of systemic IgE or positive skin test (Matsuwaki et al. 2013). This implies that there is no direct route leading from allergy to the development of CRS but rather a common pathway.

The effect of $\operatorname{IgE}$ is interesting as patients with negative allergy tests and no obvious sensitization to aeroallergens seem to also benefit from an $\operatorname{IgE}$ binding therapy (Omalizumab). However a recent systematic review on the use of anti- $\operatorname{IgE}$ monoclonal therapy for the treatment of chronic rhinosinusitis based on two randomized controlled trials did not show sufficient effectiveness of anti-IgE in the treatment of CRS (Hong et al. 2015). Local IgE levels might play a significant role and constitute an important mechanism in nonallergic inflammation, producing some of the variable clinical effects seen in allergen avoidance and allergen immunotherapy.

Maybe allergy is a disease-modifying factor in CRS, as proposed by different authors (Terzakis and Georgalas 2017). This idea could account for our results. Although disease severity did not appear to be significantly influenced by the presence of allergy, allergy might accelerate disease progression resulting in patients presenting earlier and predisposing them to a worst clinical outcome postoperatively, thus resulting in higher surgery revision rates. 


\subsection{Limitations}

The first limitation of our study arises from the fact that we have grouped our cohort of patients with CRS based on the EPOS guidelines, only into the 2 traditionally accepted subdivisions - CRSwNP and CRSsNP. This description relies on observable clinical findings but fails to include immunopathological mechanisms. There is increasing evidence that CRS encompasses a complex group of immunopathological distinct disorders with several clinical phenotypes. In a multicenter study by Tomassen et al. (2016) 10 different endotypes were identified using cluster analysis of biomarkers. Inflammation in CRS is more diverse than previously thought and this of course has significant influences on research regarding CRS and allergy. Endotyping patients within these phenotypes could be the key in understanding the complex immunology and drawing more correct conclusions regarding the effect of allergy on the disease. However, the use of inflammatory endotyping is currently at an early experimental level that has not been tested and is still not used in everyday clinical practice.

The second limitation involves the use of the LMS system as a measure of CRS disease severity, a scoring system that is by no means perfect. The major limitation arises from the fact that the LMS scores any partial opacification identically, giving it 1 point, thereby attributing equal values to both the presence of $20 \%$ opacification and $60 \%$ opacification, which have different clinical outcomes. Secondly, it has been shown by some authors that there is no association between LMS and subjective disease severity (symptoms) as well as quality of life (Hopkins et al. 2007).

The third limitation that should be acknowledged is that the timing of CT scan of the nasal sinuses has not been taken into account in our study. This means that patients with a seasonal allergy could potentially have a significantly worse LMS during the allergy season compared to other times, thus influencing the study results.

Finally, our study is a retrospective study, carrying all the limitations of retrospective studies such as selection and information bias. However, as far as we are aware, there are no prospective studies that have addressed this topic in the past. 


\section{Conclusion}

The role of allergic rhinitis as a causative immunopathological factor in chronic rhinosinusitis is controversial despite extensive investigation in the last 20 years. To further explore this relationship, we conducted a retrospective analysis of patients with chronic rhinosinusitis.

A total of 938 consecutive cases between November 2012 and November 2016 were analyzed. In our study we included 195 patients referred to our university-based allergy and sinus clinic with chronic rhinosinusitis who were not previously operated. All these patients were thoroughly investigated with computed tomography scan, skin-prick testing, total and specific serum IgE measurements and nasal provocation. We recorded demographic data and scored the severity of sinus disease in computed tomography scans using the Lund Mackay Score.

There were a total of 115 patients with chronic rhinosinusitis without evidence of an allergy based on a negative skin prick and serum $\operatorname{IgE}$ measurements and 80 patients with chronic rhinosinusitis and allergic rhinitis. There was no statistical significance in the Lund Mackay Score when comparing the two groups and the presence of asthma. The type of allergic rhinitis (seasonal, perennial, mixed) did not have a significant effect on the Lund Mackay Score. There was no statistical significance between allergic rhinitis and the presence of postoperative complications (major and minor complications). We found a statistically significant association between allergic rhinitis and the necessity of revision surgery $(\mathrm{p}=$ $0.0324)$ as well as a positive association between the presence of asthma and allergy ( $p=$ 0.0003). Allergic patients with chronic rhinosinusitis presented 7.2 years earlier to our otorhinolaryngology clinic and were 4.7 years younger at time of operation compared to those without an allergy, both values found to be statistically significant.

Our results show a limited association between CRS severity and allergy status. However, in our study, patients with chronic rhinosinusitis and allergic rhinitis tended to present earlier, be operated at a younger age and have worst postoperative clinical outcomes compared to the non-allergic patients. 


\section{Bibliography}

Alho OP (2004): Nasal airflow, mucociliary clearance, and sinus functioning during viral colds: effects of allergic rhinitis and susceptibility to recurrent sinusitis. Am J Rhinol 18, 349-355

Annesi-Maesano I (1999): Epidemiological evidence of the occurrence of rhinitis and sinusitis in asthmatics. Allergy $\underline{54}, 7-13$

Arbes SJ, Gergen PJ, Elliott L, Zeldin DC (2005): Prevalences of positive skin test responses to 10 common allergens in the US population: results from the third national health and nutrition examination survey. J Allergy Clin Immunol 116, 377383

Asaka D, Nakayama T, Hama T, Okushi T, Matsuwaki Y, Yoshikawa M, Yanagi K, Moriyama H, Otori N (2012): Risk factors for complications of endoscopic sinus surgery for chronic rhinosinusitis. Am J Rhinol Allergy 26, 61-64

Asero R, Bottazzi G (2001): Nasal polyposis: a study of its association with airborne allergen hypersensitivity. Ann Allergy Asthma Immunol 86, 283-285

Aurora R, Chatterjee D, Hentzleman J, Prasad G, Sindwani R, Sanford T (2013): Contrasting the microbiomes from healthy volunteers and patients with chronic rhinosinusitis. JAMA Otolaryngol Head Neck Surg 139, 1328-1338

Baroody FM, Mucha SM, deTineo M, Naclerio RM (2008): Nasal challenge with allergen leads to maxillary sinus inflammation. J Allergy Clin Immunol 121, 1126-1132

Baroody FM, Mucha SM, deTineo M, Naclerio RM (2012): Evidence of maxillary sinus inflammation in seasonal allergic rhinitis. Otolaryngol Head Neck Surg 146, 880 886

Batra PS, Tong L, Citardi MJ (2013): Analysis of comorbidities and objective parameters in refractory chronic rhinosinusitis. The Laryngoscope $\underline{123}$, s1-s11

Bauchau V, Durham SR (2005): Epidemiological characterization of the intermittent and persistent types of allergic rhinitis. Allergy $\underline{60}, 350-353$

Bellanti JA, Wallerstedt DB (2000): Allergic rhinitis update: epidemiology and natural history. Allergy Asthma Proc 21, 367-370

Berrettini S, Carabelli A, Sellari-Franceschini S, Bruschini L, Quartieri F, Sconosciuto F, Abruzzese A (1999): Perennial allergic rhinitis and chronic sinusitis: correlation with rhinologic risk factors. Allergy $\underline{54}$, 242-248

Beule A (2015): Epidemiology of chronic rhinosinusitis, selected risk factors, comorbidities, and economic burden. GMS Current Topics in Otorhinolaryngology, Head and Neck Surgery 14, 1-31

Bhattacharyya N, Fried MP (2003): The accuracy of computed tomography in the diagnosis of chronic rhinosinusitis. Laryngoscope $\underline{113}, 125-129$ 
Biswas K, Hoggard M, Jain R, Taylor MW, Douglas RG (2015): The nasal microbiota in health and disease: variation within and between subjects. Front Microbiol $\underline{9}, 134$

Blair C, Nelson M, Thompson K, Boonlayangoor S, Haney L, Gabr U, Baroody FM, Naclerio RM (2001): Allergic inflammation enhances bacterial sinusitis in mice. J Allergy Clin Immunol 108, 424-429

Boase S, Foreman A, Cleland E, Tan L, Melton-Kreft R, Pant H, Hu FZ, Ehrlich GD, Wormald PJ (2013): The microbiome of chronic rhinosinusitis: culture, molecular diagnostics and biofilm detection. BMC Infect Dis $\underline{13}, 210$

Bozzo C, Fenu G, Stomeo F, Meloni F, Cau M, Montella A (2005): Cytomorphologic and ultrastructural study of nasal mucosa by means of brushing: a comparison between asymptomatic and rhinitic subjects. Rhinology $\underline{43}, 261-265$

Brook CD, Kuperstock JE, Rubin SJ, Ryan MW, Platt MP (2017): The association of allergic sensitization with radiographic sinus opacification. Am J Rhinol Allergy $\underline{31}$, $12-15$

Burbank AJ, Sood AK, Kesic MJ, Peden DB, Hernandez ML (2017): Environmental determinants of allergy and asthma in early life. J Allergy Clin Immunol 140, 1-12

Burrows B, Martinez FD, Halonen M, Barbee RA, Cline MG (1989): Association of asthma with serum IgE Levels and skin-test reactivity to allergens. N Engl J Med $\underline{320}$, 271277

Calus L, Van Bruaene N, Bosteels C, Dejonckheere S, Van Zele T, Holtappels G, Bachert C, Gevaert P (2019): Twelve-year follow-up study after endoscopic sinus surgery in patients with chronic rhinosinusitis with nasal polyposis. Clin Transl Allergy $\underline{9}, 30$

Carney AS, Tan LW, Adams D, Varelias A, Ooi EH, Wormald PJ (2006): Th2 immunological inflammation in allergic fungal sinusitis, nonallergic eosinophilic fungal sinusitis, and chronic rhinosinusitis. Am J Rhinol 20, 145-149

Chivato T, Valovirta E, Dahl R, de Monchy J, Thomsen AB, Palkonen S, Jacobsen L (2012): Allergy, living and learning: diagnosis and treatment of allergic respiratory diseases in Europe. J Investig Allergol Clin Immunol 22, 168-179

Chou TW, Chen PS, Lin HC, Lee KS, Tsai HT, Lee JC, Leu YS, Wang YP (2016): Multiple analyses of factors related to complications in endoscopic sinus surgery. J Chin Med Assoc 79, 88-92

Cousins DJ, McDonald J, Lee TH (2008): Therapeutic approaches for control of transcription factors in allergic disease. J Allergy Clin Immunol 121, 803-809

Daines SM, Orlandi RR (2010): Inflammatory cytokines in allergy and rhinosinusitis: Curr Opin Otolaryngol Head Neck Surg 18, 187-190

Daley D (2014): The evolution of the hygiene hypothesis: the role of early-life exposures to viruses and microbes and their relationship to asthma and allergic diseases. Curr Opin Allergy Clin Immunol 14, 390-396 
D’Amato G, Pawankar R, Vitale C, Lanza M, Molino A, Stanziola A, Sanduzzi A, Vatrella A, D'Amato M (2016): Climate change and air pollution: effects on respiratory allergy. Allergy Asthma Immunol Res $\underline{8}, 391-395$

DeConde AS, Mace JC, Levy JM, Rudmik L, Alt JA, Smith TL (2017): Prevalence of polyp recurrence after endoscopic sinus surgery for chronic rhinosinusitis with nasal polyposis. Laryngoscope $\underline{127}, 550-555$

Denburg JA: Allergy and allergic diseases: the new mechanisms and therapeutics. $1^{\text {st }}$ Edition; Springer Science \& Business Media, New York 2013

Dreborg S, Frew A (1993): Position paper: allergen standardization and skin tests. Allergy $\underline{48}, 49-54$

Emanuel IA, Shah SB (2000): Chronic rhinosinusitis: Allergy and sinus computed tomography relationships. Otolaryngol Head Neck Surg 123, 687-691

Erskine SE, Hopkins C, Clark A, Anari S, Robertson A, Sunkaraneni V, Wilson JA, Beezhold J, Philpott CM (2017): Chronic rhinosinusitis and mood disturbance. Rhinology $\underline{55}, 113-119$

Ference EH, Stubbs V, Lidder AK, Chandra RK, Conley D, Avila PC, Hirsch AG, Min JY, Shintani Smith S, Kern RC, Tan BK (2015): Measurement and comparison of health utility assessments in chronic rhinosinusitis. Int Forum Allergy Rhinol $\underline{5}$, 929-936

Fokkens WJ, Lund VJ, Mullol J, Bachert C, Alobid I, Baroody F, Cohen N, Cervin A, Douglas R, Gevaert P, et al. (2012): EPOS 2012: European position paper on rhinosinusitis and nasal polyps 2012. A summary for otorhinolaryngologists. Rhinology $\underline{50}, 1-12$

Foreman A, Holtappels G, Psaltis AJ, Jervis-Bardy J, Field J, Wormald PJ, Bachert C (2011): Adaptive immune responses in Staphylococcus aureus biofilm-associated chronic rhinosinusitis. Allergy $\underline{66}, 1449-1456$

Friedman WH (1975): Surgery for chronic hyperplastic rhinosinusitis. Laryngoscope $\underline{85}$, 1999-2010

Geißler K, Guntinas-Lichius O (2015): Allergische Rhinitis im Kontext der chronischen Rhinosinusitis. Laryngorhinootologie 94, 250-269

Gentile D, Bartholow A, Valovirta E, Scadding G, Skoner D (2013): Current and future directions in pediatric allergic rhinitis. J Allergy Clin Immunol Pract 1, 214-226

Georgalas C, Vlastos I, Picavet V, Van Drunen C, Garas G, Prokopakis E (2014): Is chronic rhinosinusitis related to allergic rhinitis in adults and children? Applying epidemiological guidelines for causation. Allergy $\underline{69}$, 828-833

Gosepath J, Amedee RG, Mann WJ (2005): Nasal provocation testing as an international standard for evaluation of allergic and nonallergic rhinitis. Laryngoscope $\underline{115}, 512$ 516

Greiwe JC, Bernstein JA (2019): Allergic and mixed rhinitis: diagnosis and natural evolution. J Clin Med $\underline{8}, 1-10$ 
Grigoreas C, Vourdas D, Petalas K, Simeonidis G, Demeroutis I, Tsioulos T (2002): Nasal polyps in patients with rhinitis and asthma. Allergy Asthma Proc 23, 169-174

Gutman M, Torres A, Keen KJ, Houser SM (2004): Prevalence of allergy in patients with chronic rhinosinusitis. Otolaryngol Head Neck Surg $\underline{130}, 545-552$

Haftenberger M, Laußmann D, Ellert U, Kalcklösch M, Langen U, Schlaud M, Schmitz R, Thamm M (2013): Prävalenz von Sensibilisierungen gegen Inhalations- und Nahrungsmittelallergene: Ergebnisse der Studie zur Gesundheit Erwachsener in Deutschland (DEGS1). Bundesgesundheitsblatt - Gesundheitsforschung Gesundheitsschutz ㅁ, 687-697

Hamizan AW, Loftus PA, Alvarado R, Ho J, Kalish L, Sacks R, DelGaudio JM, Harvey RJ (2018): Allergic phenotype of chronic rhinosinusitis based on radiologic pattern of disease. Laryngoscope 128, 2015-2021

Head K, Chong LY, Hopkins C, Philpott C, Burton MJ, Schilder AG (2016): Short-course oral steroids alone for chronic rhinosinusitis. Cochrane Database Syst Rev $\underline{4}$, CD011991

Hellings PW, Fokkens WJ, Bachert C, Akdis CA, Bieber T, Agache I, Bernal-Sprekelsen M, Canonica GW, Gevaert P, Joos G, et al. (2017): Positioning the principles of precision medicine in care pathways for allergic rhinitis and chronic rhinosinusitis A EUFOREA-ARIA-EPOS-AIRWAYS ICP statement. Allergy 72, 1297-1305

Hong CJ, Tsang AC, Quinn JG, Bonaparte JP, Stevens A, Kilty SJ (2015): Anti-IgE monoclonal antibody therapy for the treatment of chronic rhinosinusitis: a systematic review. Syst Rev $\underline{4}, 166$

Hopkins C, Browne J, Slack R, Lund V, Brown P (2007): The Lund-Mackay staging system for chronic rhinosinusitis: How is it used and what does it predict? Otolaryngol Head Neck Surg 137, 555-561

Hopkins C, Slack R, Lund V, Brown P, Copley L, Browne J (2009): Long-term outcomes from the English national comparative audit of surgery for nasal polyposis and chronic rhinosinusitis. The Laryngoscope 119, 2459-2465

Houser SM, Keen KJ (2008): The role of allergy and smoking in chronic rhinosinusitis and polyposis. Laryngoscope $\underline{118}, 1521-1527$

Jarvis D, Newson R, Lotvall J, Hastan D, Tomassen P, Keil T, Gjomarkaj M, Forsberg B, Gunnbjornsdottir M, Minov J, et al. (2012): Asthma in adults and its association with chronic rhinosinusitis: The GA2LEN survey in Europe: Asthma and chronic rhinosinusitis. Allergy $\underline{67}, 91-98$

Johansson SG (2004a): ImmunoCAP® Specific IgE test: an objective tool for research and routine allergy diagnosis. Expert Rev Mol Diagn 4, 273-279

Johansson SG, Bieber T, Dahl R, Friedmann PS, Lanier BQ, Lockey RF, Motala C, Ortega Martell JA, Platts-Mills TAE, Ring J (2004b): Revised nomenclature for allergy for global use: Report of the nomenclature review committee of the World Allergy Organization, October 2003. J Allergy Clin Immunol 113, 832-836 
Kawauchi H, Yanai K, Wang DY, Itahashi K, Okubo K (2019): Antihistamines for allergic rhinitis treatment from the viewpoint of nonsedative properties. Int J Mol Sci $\underline{20}$, 213

Khalmuratova R, Park JW, Shin HW (2017): Immune cell responses and mucosal barrier disruptions in chronic rhinosinusitis. Immune Netw $\underline{17}, 60-67$

Kim DK, Jin HR, Eun KM, Mutusamy S, Cho SH, Oh S, Kim DW (2015): Noneosinophilic nasal polyps shows increased epithelial proliferation and localized disease pattern in the early stage. PLoS One $\underline{10}$, e0139945

Koskinen A, Salo R, Huhtala H, Myller J, Rautiainen M, Kääriäinen J, Penttilä M, Renkonen R, Raitiola H, Mäkelä M, Toppila-Salmi S (2016): Factors affecting revision rate of chronic rhinosinusitis. Laryngoscope Investig Otolaryngol 1 , $96-$ 105

Krouse JH (2000): Computed tomography stage, allergy testing, and quality of life in patients with sinusitis. Otolaryngol Head Neck Surg 123, 389-392

Langen U, Schmitz R, Steppuhn H (2013): Häufigkeit allergischer Erkrankungen in Deutschland. Bundesgesundheitsbl 56, 698-706

Leo G, Piacentini E, Incorvaia C, Consonni D, Frati F (2007): Chronic rhinosinusitis and allergy. Pediatr Allergy Immunol 18, 19-21

Li Q, Cheng K, Wang F, Zhou S (2016): Role of atopy in chronic rhinosinusitis with nasal polyps: does an atopic condition affect the severity and recurrence of disease? J Laryngol Otol 130, 640-644

London NR, Lane AP (2016): Innate immunity and chronic rhinosinusitis: What we have learned from animal models. Laryngoscope Investig Otolaryngol 1, 49-56

Luk LJ, DelGaudio JM (2017): Topical drug therapies for chronic rhinosinusitis. Otolaryngol Clin North Am $\underline{50}$, 533-543

Lund VJ, Mackay IS (1993): Staging in rhinosinusitus. Rhinology $\underline{31}, 183-184$

Mahdavinia M (2018): The nasal microbiome: opening new clinical research avenues for allergic disease. Expert Rev Clin Immunol 14, 645-647

Matsuwaki Y, Uno K, Okushi T, Otori N, Moriyama H (2013): Total and antigen- (fungi, mites and staphylococcal enterotoxins) specific IgEs in nasal polyps is related to local eosinophilic inflammation. IAA $\underline{161}, 147-153$

Maziak W, Behrens T, Brasky TM, Duhme H, Rzehak P, Weiland SK, Keil U (2003): Are asthma and allergies in children and adolescents increasing? Results from ISAAC phase I and phase III surveys in Münster, Germany. Allergy 58, 572-579

Min YG, Jung HW, Kim HS, Park SK, Yoo KY (1996): Prevalence and risk factors of chronic sinusitis in Korea: results of a nationwide survey. Eur Arch Otorhinolaryngol 253, 435-439

Murrison LB, Brandt EB, Myers JB, Hershey GKK (2019): Environmental exposures and mechanisms in allergy and asthma development. J Clin Invest 129, 1504-1515 
Naclerio RM, Bachert C, Baraniuk JN (2010): Pathophysiology of nasal congestion. Int J Gen Med $\underline{3}, 47-57$

Ooi EH, Psaltis AJ, Witterick IJ, Wormald PJ (2010): Innate immunity. Otolaryngol Clin North Am $\underline{43}, 473-487$

Palmer JN, Messina JC, Biletch R, Grosel K, Mahmoud RA (2019): A cross-sectional, population-based survey of U.S. adults with symptoms of chronic rhinosinusitis. Allergy Asthma Proc 40, 48-56

Passàli D, Bellussi L, Lauriello M, Passali D (1995): The rheological characteristics of nasal mucus in patients with rhinitis. Eur Arch Otorhinolaryngol 252, 348-352

Passàli D, Ferri R, Becchini G, Passàli GC, Bellussi L (1999): Alterations of nasal mucociliary transport in patients with hypertrophy of the inferior turbinates, deviations of the nasal septum and chronic sinusitis. Eur Arch Otorhinolaryng 256, 335-337

Pearlman AN, Chandra RK, Chang D, Conley DB, Peters AT, Grammer LC, Schleimer RT, Kern RC (2009): Relationships between severity of chronic rhinosinusitis and nasal polyposis, asthma, and atopy. Am J Rhinol Allergy 23, 145-148

Petersen K (2008): Impact of allergy and asthma on quality of life and comparison with other diseases. Drugs Today $\underline{44}, 17-18$

Pfaar O, Bachert C, Bufe A, Buhl R, Ebner C, Eng P, Friedrichs F, Fuchs T, Hamelmann E, Hartwig-Bade D, et al. (2014): Guideline on allergen-specific immunotherapy in IgE-mediated allergic diseases. Allergo J Int 23, 282-319

Promsopa C, Kansara S, Citardi MJ, Fakhri S, Porter P, Luong A (2016): Prevalence of confirmed asthma varies in chronic rhinosinusitis subtypes. Int Forum Allergy Rhinol $\underline{6}, 373-377$

Ramadan HH, Fornelli R, Ortiz AO, Rodman S (1999): Correlation of Allergy and Severity of Sinus Disease. Am J Rhinol 13, 345-347

Ramakrishnan VR, Hauser LJ, Feazel LM, Ir D, Robertson CE, Frank DN (2015): Sinus microbiota varies among chronic rhinosinusitis phenotypes and predicts surgical outcome. J Allergy Clin Immunol 136, 334-342

Ramanathan M, Lane AP (2007): Innate immunity of the sinonasal cavity and its role in chronic rhinosinusitis. Otolaryngol Head Neck Surg 136, 348-356

Renz H, Biedermann T, Bufe A, Eberlein B, Jappe U, Petersen A, Kleine-Tebbe J, RaulfHeimsoth M, Saloga J, Worm M (2010): In-vitro-Allergiediagnostik. Allergo J $\underline{19}$, 110-28

Riechelmann H, Bachert C, Goldschmidt O, Hauswald B, Klimek L, Schlenter W, Tasman A, Wagenmann M (2003): Application of the nasal provocation test on diseases of the upper airways. Position paper of the German Society for Allergology and Clinical Immunology (ENT Section) in cooperation with the working team for clinical immunology. Laryngorhinootologie $\underline{\text { 82, }}$ 183-188 
Riechelmann H, Deutschle T, Rozsasi A, Keck T, Polzehl D, Bürner H (2005): Nasal biomarker profiles in acute and chronic rhinosinusitis. Clin Exp Allergy $\underline{35}, 1186$ 1191

Robinson S, Douglas R, Wormald PJ (2006): The relationship between atopy and chronic rhinosinusitis. Am J Rhinol 20, 625-628

Rondón C, Romero JJ, López S, Antúnez C, Martín-Casañez E, Torres MJ, Mayorga C, RPena R, Blanca M (2007): Local IgE production and positive nasal provocation test in patients with persistent nonallergic rhinitis. J Allergy Clin Immunol 119, 899-905

Ruëff F, Bergmann KC, Brockow K, Fuchs T, Grübl A, Jung K, Klimek L, Müsken H, Pfaar O, Przybilla B, et al. (2011): Hauttests zur Diagnostik von allergischen Soforttyp-Reaktionen. Pneumologie 65, 484-495

Schlaud M, Atzpodien K, Thierfelder W (2007): Allergische Erkrankungen: Ergebnisse aus dem Kinder- und Jugendgesundheitssurvey (KiGGS). Bundesgesundheitsbl 무, $701-710$

Schröder K, Finis D, Meller S, Buhren BA, Wagenmann M, Geerling G (2017): Die saisonale und perenniale allergische Rhinokonjunktivitis. Laryngorhinootologie $\underline{96}$, 89-97

Seidman MD, Gurgel RK, Lin SY, Schwartz SR, Baroody FM, Bonner JR, Dawson DE, Dykewicz MS, Hackell JM, Han JK, et al. (2015): Clinical Practice Guideline: Allergic Rhinitis. Otolaryngol Head Neck Surg 152, 1-43

Settipane G, Chafee F (1977): Nasal polyps in asthma and rhinitis: a review of 6,037 patients. J Allergy Clin Immunol $\underline{59}, 17-21$

Settipane RA, Charnock DR (2007): Epidemiology of rhinitis: allergic and nonallergic. Clin Allergy Immunol $\underline{19}, 23-34$

Shen KC, Lin YT, Lin CF, Chang CH, Yeh TH (2019): Allergy accelerates the disease progression of chronic rhinosinusitis. Acta Otolaryngol $\underline{139}, 75-79$

Shi JB, Fu QL, Zhang H, Cheng L, Wang YJ, Zhu DD, Lv W, Liu SX, Li PZ, Ou CQ, Xu $G$ (2015): Epidemiology of chronic rhinosinusitis: results from a cross-sectional survey in seven Chinese cities. Allergy $\underline{70}$, 533-539

Skoner DP (2001): Allergic rhinitis: Definition, epidemiology, pathophysiology, detection, and diagnosis. J Allergy Clin Immunol $\underline{108}, 2-8$

Smith KA, Orlandi RR, Oakley G, Meeks H, Curtin K, Alt JA (2019): Long-term revision rates for endoscopic sinus surgery. Int Forum Allergy Rhinol $\underline{9}$, 402-408

Stone KD, Prussin C, Metcalfe DD (2010): IgE, mast cells, basophils, and eosinophils. J Allergy Clin Immunol 125, 73-80

Stuck BA, Beule A, Jobst D, Klimek L, Laudien M, Lell M, Vogl TJ, Popert U (2018): Leitlinie „Rhinosinusitis“ - Langfassung. HNO $\underline{66}, 38-74$ 
Suzuki M, Watanabe T, Suko T, Mogi G (1999): Comparison of sinusitis with and without allergic rhinitis: Characteristics of paranasal sinus effusion and mucosa. Am J Otolaryngol 20, 143-150

Tan BK, Schleimer RP, Kern RC (2010): Perspectives on the etiology of chronic rhinosinusitis. Curr Opin Otolaryngol Head Neck Surg 18, 21

Tan BK, Zirkle W, Chandra RK, Lin D, Conley DB, Peters AT, Grammer LC, Schleimer RP, Kern RC (2011): Atopic profile of patients failing medical therapy for chronic rhinosinusitis. Int Forum Allergy Rhinol 1, 88-94

Tan BK, Kern RC, Schleimer RP, Schwartz BS (2013a): Chronic rhinosinusitis: The unrecognized epidemic. Am J Respir Crit Care Med 188, 1275-1277

Tan BK, Chandra RK, Pollak J, Kato A, Conley DB, Peters AT, Grammer LC, Avila PC, Kern RC, Stewart WF, et al. (2013b): Incidence and associated premorbid diagnoses of patients with chronic rhinosinusitis. J Allergy Clin Immunol 131, $1350-1360$

Terzakis D, Georgalas C (2017): Polyps, asthma, and allergy: what's new. Curr Opin Otolaryngol Head Neck Surg 25, 12-18

Tieu DD, Kern RC, Schleimer RP (2009): Alterations in epithelial barrier function and host defense responses in chronic rhinosinusitis. J Allergy Clin Immunol 124, 37-42

Tomassen P, Vandeplas G, Van Zele T, Cardell LO, Arebro J, Olze H, Förster-Ruhrmann U, Kowalski ML, Olszewska-Ziaber A, Holtappels G, et al. (2016): Inflammatory endotypes of chronic rhinosinusitis based on cluster analysis of biomarkers. J Allergy Clin Immunol 137, 1449-1456

Tyler MA, Luong AU (2018): Current understanding of allergic fungal rhinosinusitis. World J Otorhinolaryngol Head Neck Surg 4, 179-185

Van Bruaene N, Derycke L, Perez-Novo CA, Gevaert P, Holtappels G, Ruyck ND, Cuvelier C, Van Cauwenberge P, Bachert C (2009): TGF- $\beta$ signaling and collagen deposition in chronic rhinosinusitis. J Allergy Clin Immunol 124, 253-259

Van Cauwenberge P, Hoecke HV, Bachert C (2006): Pathogenesis of chronic rhinosinusitis. Curr Allergy Asthma Rep $\underline{6}$, 487-494

Van Zele T, Gevaert P, Watelet J-B, Claeys G, Holtappels G, Claeys C, van Cauwenberge P, Bachert C (2004): Staphylococcus aureus colonization and $\operatorname{IgE}$ antibody formation to enterotoxins is increased in nasal polyposis. J Allergy Clin Immunol $\underline{114}, 981-983$

Van Zele T, Claeys S, Gevaert P, Van Maele G, Holtappels G, Van Cauwenberge P, Bachert C (2006): Differentiation of chronic sinus diseases by measurement of inflammatory mediators. Allergy $\underline{61}, 1280-1289$

Weber RK, Hosemann W (2015): Comprehensive review on endonasal endoscopic sinus surgery. GMS Curr Top Otorhinolaryngol Head Neck Surg 14, Doc08 
Wilson KF, McMains KC, Orlandi RR (2014): The association between allergy and chronic rhinosinusitis with and without nasal polyps: an evidence-based review with recommendations. Int Forum Allergy Rhinol 4, 93-103

Wu PW, Huang CC, Yang SW, Huang Y, Huang CC, Chang PH, Lee YS, Lee TJ (2020): Endoscopic sinus surgery for pediatric patients: Prognostic factors related to revision surgery. Laryngoscope. 130, 1051-1055

Zhang N, Holtappels G, Claeys C, Huang G, Van Cauwenberge P, Bachert C (2006): Pattern of inflammation and impact of staphylococcus aureus enterotoxins in nasal polyps from southern China. Am J Rhinol 20, 445-450

Zhang N, Van Zele T, Perez-Novo C, Van Bruaene N, Holtappels G, DeRuyck N, van Cauwenberge P, Bachert C (2008): Different types of T-effector cells orchestrate mucosal inflammation in chronic sinus disease. J Allergy Clin Immunol 122, 961968

Zhang N, Crombruggen KV, Gevaert E, Bachert C (2016): Barrier function of the nasal mucosa in health and type-2 biased airway diseases. Allergy 71, 295-307 


\section{Acknowledgements}

I would like to express my deep gratitude to my research supervisor Prof. Dr. med. F. Ihler for giving me the opportunity to do research and providing guidance throughout this project. I am extending my sincere thanks to my second supervisor Prof. Dr. med. T. Buhl for his motivation and insightful comments.

My special thanks goes to my friend and colleague Dr. med. Eirini Mavropoulou for her continuing support to complete this research work. I would like to thank Dr. med. Moritz Hollstein for his technical support and Dr. med. Ismini Papageorgiou for her radiological assistance. 